\title{
Anti-alcohol and anxiolytic properties of a new chemical entity, GET73
}

\section{Antonella Loche ${ }^{1 *}$, Francesco Simonetti ${ }^{1}$, Carla Lobina ${ }^{2}$, Mauro A. M. Carai ${ }^{2}$, Giancarlo Colombo ${ }^{2}$, M. Paola Castelli ${ }^{3}$, Domenico Barone ${ }^{4}$ and Roberto Cacciaglia ${ }^{1}$}

\author{
${ }^{1}$ Laboratorio CT srl, Sanremo, Italy \\ ${ }^{2}$ Section of Cagliari, Neuroscience Institute, National Research Council of Italy, Cagliari, Italy \\ 3 "Bernard B. Brodie" Department of Neuroscience, University of Cagliari, Cagliari, Italy \\ ${ }^{4}$ Istituto di Ricerche Biomediche "A. Marxer" RBM spa, Colleretto Giacosa, Italy
}

\section{Edited by: \\ Lorenzo Leggio, Brown University, USA}

\section{Reviewed by:}

Maria E. Quintanilla, Universidad de Chile, Chile

Jose Antonio Lopez-Moreno,

Comlutense University Madrid, Spain

*Correspondence:

Antonella Loche, Laboratorio CT srl,

Via Ludovico Ariosto 17, I-18038

Sanremo (IM), Italy.

e-mail: loche.antonella@labct.it
$\mathrm{N}$-[(4-trifluoromethyl)benzyl]4-methoxybutyramide (GET73) is a newly synthesized compound structurally related to the clinically used, alcohol-substituting agent, gammahydroxybutyric acid (GHB). The present study was designed to assess whether GET73 may share with GHB the capacity to reduce alcohol intake in rats. Additionally, the effect of treatment with GET73 on anxiety-related behaviors and cognitive tasks in rats was investigated. A series of in vitro binding assays investigated the capacity of GET73 to bind to the GHB binding site and multiple other receptors. GET73 $\left(10^{-9}-10^{-3} \mathrm{M}\right)$ failed to inhibit $\left[{ }^{3} \mathrm{H}\right] \mathrm{GHB}$ binding at both high- and low-affinity GHB recognition sites in rat cortical membranes. GET73 displayed minimal, if any, binding at dopamine, serotonin, GABA, and glutamate receptors in membranes from different rat brain areas. Acute treatment with low-to-moderate, non-sedative doses of GET73 $(5-50 \mathrm{mg} / \mathrm{kg}$, i.g. or i.p.) (a) reduced alcohol intake and suppressed "alcohol deprivation effect" (a model of alcohol relapse) in selectively bred, Sardinian alcohol-preferring (sP) rats, (b) exerted anxiolytic effects in Sprague-Dawley (SD) and SP rats exposed to the Elevated Plus Maze test, and (c) tended to induce promnestic effects in SD rats exposed to a modified water version of the HebbWilliams maze test. Although the mechanism of GET73 action is currently unknown, the results of the present study suggest that GET73 has a multifaceted pharmacological profile, including the capacity to reduce alcohol drinking and anxiety-related behaviors in rats.

Keywords: GET73, $\gamma$-hydroxybutyric acid, alcohol intake, alcohol deprivation effect, anxiety-related behaviors, Sardinian alcohol-preferring rats

\section{INTRODUCTION}

In spite of the increasing emphasis placed on alcohol use disorders (AUDs) worldwide, to date only a few therapeutic options (namely disulfiram, naltrexone, and acamprosate) have been approved and are currently available for clinical use. Moreover, the overall efficacy of these compounds is often viewed as not being completely satisfactory (see Krishnan-Sarin et al., 2008; O'Malley and O'Connor, 2011), thus underlining the need for novel, and potentially effective, pharmacological agents. Accordingly, in recent years research studies have focused on investigating multiple alternative molecular targets potentially involved in AUDs, and testing drugs capable of modulating these neural systems and affecting different alcohol-related behaviors.

The outcome of these studies has resulted in the development of gamma-hydroxybutyric acid (GHB) for use in the treatment of alcohol dependence. GHB is an endogenous constituent of the mammalian brain, with a neurotransmitter and/or neuromodulator profile (see Snead and Gibson, 2005; Carter et al., 2009; Agabio et al., 2010; Andresen et al., 2011). A series of experimental data have provided confirmation of its capacity to reduce different alcohol-related behaviors, including alcohol intake under the homecage two-bottle choice and oral alcohol self-administration under standard operant procedures, in selectively bred, Sardinian alcohol-preferring (sP; Agabio et al., 1998; Maccioni et al., 2008), and Indiana alcohol-preferring (P; June et al., 1995) rats. Open and double-blind clinical trials, as well as several case reports, have demonstrated the capacity of GHB to (a) reduce alcohol craving and consumption, (b) promote and maintain abstinence from alcohol, and (c) ameliorate signs and symptoms of alcohol withdrawal syndrome in alcoholics (e.g., Gallimberti et al., 1989, 1992; Addolorato et al., 1996, 1998a,b, 1999; Moncini et al., 2000; Glisson and Norton, 2002; Nimmerrichter et al., 2002; for review, see Agabio and Gessa, 2002; Addolorato et al., 2009; Caputo et al., 2010; Chick and Nutt, 2012). These data have led to GHB obtaining approval as a pharmacotherapy for alcohol dependence in Italy and other European Countries.

The present paper is intended to illustrate the anti-alcohol and anxiolytic properties of $\mathrm{N}$-[(4-trifluoromethyl)benzyl]4methoxybutyramide (GET73), a newly synthesized compound structurally related to GHB (Figure 1). GET73 was initially designed as a GHB derivative, thought to possess a more favorable pharmacodynamic and pharmacokinetic profile. The pharmacological characterization of GET73 conducted in the present study included: (a) binding assays to evaluate the capacity of GET73 to 


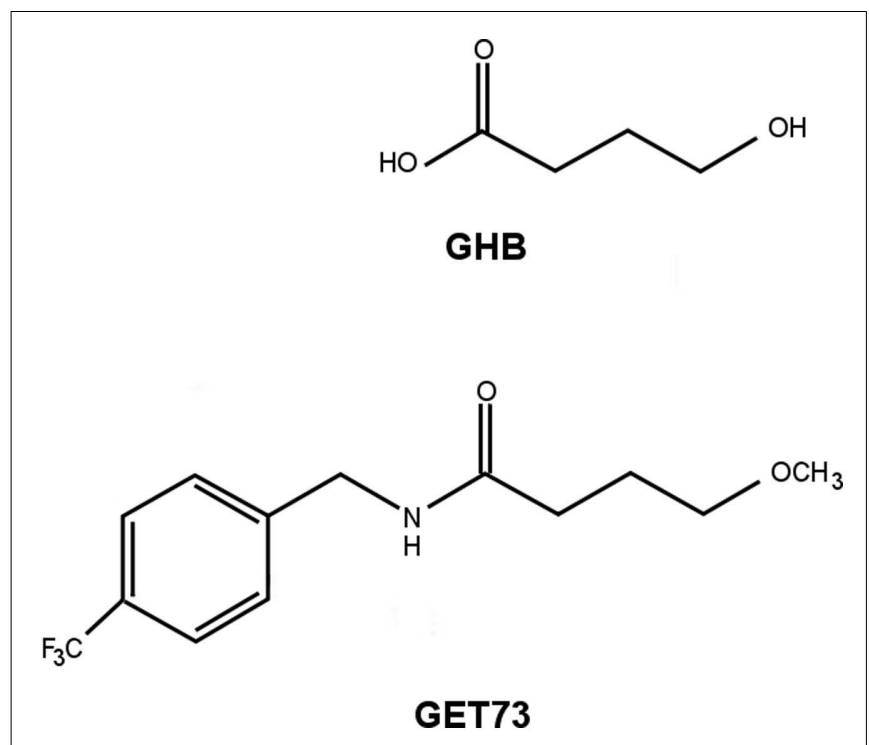

FIGURE 1 | Molecular structure of GHB and GET73.

bind to the GHB binding site (Experiment 1) as well as other receptor systems (Experiment 2); (b) evaluation of GET73 effects on spontaneous locomotor activity (Experiment 3), cognitive functions (Experiments 4-6), and anxiety-related behaviors (Experiment 7) in Sprague-Dawley (SD) and sP rats; (c) investigation on the capacity of GET73 to affect alcohol drinking behavior and relapse-like drinking in $\mathrm{sP}$ rats (Experiments 8 and 9).

\section{MATERIALS AND METHODS}

All experimental procedures employed in the present study were conducted in accordance with the European Community ethical regulations on the care of animal for scientific research (CEE 86/609).

\section{ANIMALS}

Experiments 1-7a employed male SD rats (Harlan, San Pietro al Natisone, Italy), weighing 200-300 g. Experiments 7b, 8, and 9 employed male sP rats, 75 days old and weighing 300-350 g at the start of each experiment. A total of 248 SD and $296 \mathrm{sP}$ rats were used. Rats of the sP line belonged to generations 60-62 and 65 in Experiments 8 and 9, and generation 73 in Experiment 7b. Experiments with SD and sP rats were conducted in Sanremo and Cagliari, respectively. Each experiment employed independent groups of rats.

Animal facilities were kept under standard environmental conditions $\left(22 \pm 2^{\circ} \mathrm{C} ; 55 \pm 10 \%\right.$ relative humidity) and reversed light/dark cycle (lights on at 21:00). Rats were housed either four per cage (Experiments 1-7) or individually (Experiments 8 and 9) in standard plastic cages with wood chip bedding. Standard rat chow (Mucedola, Settimo Milanese, Italy) and water were always available in the homecage, except as noted below. Over the 2 weeks preceding the start of each experiment, rats underwent daily 10min sessions during which they were extensively habituated to handling and drug administration procedures.

\section{DRUGS}

In in vivo experiments, GET73 (batch M50060010; Dipharma Francis, Caronno Pertusella, Italy), was suspended in $0.5 \%$ carboxymethyl cellulose and administered either i.p. (injection volume: $2 \mathrm{ml} / \mathrm{kg}$ ) or i.g. (by metal gavage; infusion volume: $4 \mathrm{ml} / \mathrm{kg}$ ). Time of GET73 treatment was chosen on the basis of previous data in SD rats, suggesting that peak plasma concentrations are achieved $30 \mathrm{~min}$ after both intraperitoneal and oral administration. Chemicals, radioligands, and cold ligands used for binding studies were obtained from commercial sources.

\section{EXPERIMENTAL PROCEDURES}

Testing was undertaken according to standard operating protocols by trained personnel blinded to the treatment conditions. All behavioral procedures were conducted during the dark phase of the light/dark cycle, in quiet, dimly lit rooms, adjacent to the housing room.

\section{Experiment 1: $\left.{ }^{\beta} \mathrm{H}\right] \mathrm{GHB}$ binding assay}

The GHB binding assay was carried out on rat cerebral cortex. The tissue was processed as previously described (Castelli et al., 2003). Briefly, rats were killed by decapitation, their brains rapidly removed, and cerebral cortices dissected on ice. The tissue was homogenized in 20 volumes $(\mathrm{v} / \mathrm{w})$ of ice-cold $0.32 \mathrm{M}$ sucrose, containing $1 \mathrm{mM}$ EDTA, using a homogenizer system (Glass-Col, Terre Haute, IN, USA). The homogenate was centrifuged at $1,000 \mathrm{~g}$ for $10 \mathrm{~min}$ and the supernatant collected and recentrifuged at $20,000 \mathrm{~g}$ for $20 \mathrm{~min}$. The pellet was resuspended in 20 volumes $(\mathrm{v} / \mathrm{w})$ of ice-cold water, homogenized using a Polytron homogenizer, and centrifuged at $8,000 \mathrm{~g}$ for $20 \mathrm{~min}$. The supernatant, together with the buffy layer on the pellet, was then centrifuged at $45,000 \mathrm{~g}$ for $20 \mathrm{~min}$. The resulting pellet was resuspended in ice-cold distilled water and once more centrifuged at 45,000 $g$ for $30 \mathrm{~min}$. Homogenization and centrifugation in water was performed to lyse the tissue and wash out endogenous GHB. The final pellet was frozen and stored at $-80^{\circ} \mathrm{C}$ for at least $18 \mathrm{~h}$ before binding assay. Membrane pellets were allowed to thaw at $4^{\circ} \mathrm{C}$ before resuspension in 20 volumes $(\mathrm{v} / \mathrm{w})$ of $50 \mathrm{mM} \mathrm{KH}_{2} \mathrm{PO}_{4}$ buffer $(\mathrm{pH}$ 6.5) containing $1 \mathrm{mM}$ EDTA. The suspension was incubated for $20 \mathrm{~min}$ at $20^{\circ} \mathrm{C}$ before centrifugation at $7,000 \mathrm{~g}$ for $10 \mathrm{~min}$. The washing step was repeated three more times, allowing $15 \mathrm{~min}$ incubation with each addition of the same buffer to further remove the residual endogenous ligand GHB. The final pellet was then resuspended in $50 \mathrm{mM} \mathrm{KH}_{2} \mathrm{PO}_{4}, \mathrm{pH} 6.5$, to a final concentration of 200-300 $\mu \mathrm{g}$ of membrane protein.

$\left[{ }^{3} \mathrm{H}\right] \mathrm{GHB}$ binding assay was performed in triplicate in a volume of $0.6 \mathrm{ml}$ at $4^{\circ} \mathrm{C}$ for $30 \mathrm{~min}$. Non-specific binding was estimated in the presence of $1 \mathrm{mM}$ unlabeled GHB. Free ligand was separated from bound ligand by rapid filtration through Whatman GF/B glass filters using a Brandel 24-sample harvester (Brandel, Gaithersburg, MD, USA). Filters were then rinsed twice with icecold $50 \mathrm{mM} \mathrm{KH}_{2} \mathrm{PO}_{4}$ buffer ( $\mathrm{pH}$ 6.5) and filter-bound radioactivity was counted in a liquid scintillation counter (Packard Tri-Carb 2900; Packard, Meridien, CT, USA), using $3 \mathrm{ml}$ of scintillation fluid (Packard Ultima Gold MV). 
$\left[{ }^{3} \mathrm{H}\right] \mathrm{GHB}$ displacement curves were carried out using serial dilutions ranging from $10^{-9}$ to $10^{-3} \mathrm{M}$ of the unlabeled compound and $\left[{ }^{3} \mathrm{H}\right] \mathrm{GHB}(60 \mathrm{nM})$. Independent experiments were repeated on membrane preparations from at least three different brains.

The Bradford protein assay (Bradford, 1976) was used for protein determination using bovine serum albumin as a standard according to the protocol of the supplier (Bio-Rad, Milan, Italy).

The calculation of $\mathrm{IC}_{50}$ (concentration which inhibits $50 \%$ of specific radioligand binding) was performed by non-linear curve fitting of the concentration-effect curves using GraphPad Prism Program (San Diego, CA, USA).

\section{Experiment 2: other binding assays}

This experiment tested GET73 affinity for the following targets: dopamine $\mathrm{D}_{1}, \mathrm{D}_{2}$, and $\mathrm{D}_{3}$ receptors, serotonin $5-\mathrm{HT}_{1}, 5-\mathrm{HT}_{2}$, and $5-\mathrm{HT}_{3}$ receptors, $\mathrm{GABA}_{\mathrm{A}}$ and $\mathrm{GABA}_{\mathrm{B}}$ receptors, benzodiazepine binding site, chloride channel, ionotropic glutamate $[\alpha$-amino-3hydroxy-5-methyl-4-isoxazolepropionic acid (AMPA), $N$-methyl$\mathrm{D}$-aspartate (NMDA), and kainate] receptors, dopamine, and serotonin reuptake sites. All methodological details and references are reported in Table 1.

Rats were killed by decapitation, their brains rapidly removed, and areas dissected on ice. Brain tissue was sonicated in a Polytron PT 10 microhomogenizer (Kinematica, Littau, Switzerland) in 2550 volumes $(\mathrm{v} / \mathrm{w})$ of the appropriate buffer $(50 \mathrm{mM}$ Tris- $\mathrm{HCl}, \mathrm{pH}$ 7.4-7.7 or $10-50 \mathrm{mM} \mathrm{Na} / \mathrm{K}$ phosphate, $\mathrm{pH} 7.4$ ) complemented, when necessary, with the suitable ions. The homogenate was centrifuged three times at $50,000 \mathrm{~g}$ for $10 \mathrm{~min}$ at $4^{\circ} \mathrm{C}$, with resuspension of the intermediate pellet. The final pellet was resuspended (crude membrane synaptosomal preparation) in 50-100 volumes $(\mathrm{v} / \mathrm{w})$ of the cold incubation buffer.
GET73 or reference compounds, dissolved and diluted in incubation buffer (100-200 $\mu \mathrm{l})$ and 500-1,500 $\mu \mathrm{l}$ of radioligand solution, were put in $10 \mathrm{ml}$ polypropylene tubes. Finally, receptor preparation $(500-1,500 \mu \mathrm{l})$ was added, the incubation mixture was adjusted to the appropriate final volume $(1-2 \mathrm{ml})$ by addition of incubation buffer and the tubes were put into the incubation bath (see Table 1). The incubation was stopped and the membrane bound radioligand was separated from the free fraction by addition of $5 \mathrm{ml}$ of cold buffer and rapid filtration through glass fiber filters (GF/A or/B or/C) using a Brandel harvester (Gaithersburg, $\mathrm{MD}, \mathrm{USA}$ ). After $3 \mathrm{ml} \times 5 \mathrm{ml}$ cold buffer washings, disk filters were put into plastic vials containing $10 \mathrm{ml}$ Biofluor and radioactivity in the filters was counted by liquid scintillation spectroscopy (Packard Tri-Carb 2000 CA, counting efficiency about 55-60\%).

Binding assays were performed in triplicate and GET73 was evaluated at $10^{-4}, 10^{-5}$, and $10^{-6} \mathrm{M}$.

$\mathrm{IC}_{50}$ values of known reference drugs run in parallel to GET73 were calculated with the "ALLFIT" program. The comparison of $\mathrm{IC}_{50}$ values with the historical data base of the lab served as quality control of binding data.

\section{Experiment 3: spontaneous motor activity}

Four custom-made gray plastic test cages [ $57 \mathrm{~cm} \times 27 \mathrm{~cm} \times 30(\mathrm{~h}) \mathrm{cm}$ ] were used. Rats were not familiar to the test cage before testing. Each rat was placed in the test cage and its horizontal locomotor activity was recorded by a computer-controlled, digital camera; the computer was equipped with Smart V2.0 software (Panlab, Cornellà, Spain) for tracking analysis. The measured variable was the distance traveled (expressed in centimeter). The test cage was thoroughly cleaned after each trial.

Rats were fasted $15 \mathrm{~h}$ before GET73 administration. Rats were divided into four groups $(n=8)$ and treated acutely and i.g. with

Table 1 | Assay conditions for radioligand binding experiments.

\begin{tabular}{|c|c|c|c|c|c|}
\hline Receptor/binding site & Receptor source & [Radioligand] & $\begin{array}{l}\text { Non-specific binding } \\
\text { in the presence of }\end{array}$ & $\begin{array}{l}\text { Incubation time } \\
\text { and temperature }\end{array}$ & Reference \\
\hline Dopamine $\mathrm{D}_{1}$ & Rat striatum & $0.35 \mathrm{nM},\left[{ }^{3} \mathrm{H}\right] \mathrm{SCH} 23390$ & $3 \mu \mathrm{M}$, cis-flupenthixol & $20 \mathrm{~min}, 37^{\circ} \mathrm{C}$ & Billard et al. (1984) \\
\hline Dopamine $\mathrm{D}_{2}$ & Rat striatum & $0.15 \mathrm{nM},\left[{ }^{3} \mathrm{H}\right]$ spiperone & $3 \mu \mathrm{M},(+)$ butaclamol & $15 \mathrm{~min}, 37^{\circ} \mathrm{C}$ & Fields et al. (1977) \\
\hline Dopamine $D_{3}$ & Rat olfactory tubercles & $0.70 \mathrm{nM},\left[{ }^{3} \mathrm{H}\right] 7-\mathrm{OHDPAT}$ & $1 \mu \mathrm{M}$, dopamine & $60 \min , 25^{\circ} \mathrm{C}$ & Lévesque et al. (1992) \\
\hline Dopamine uptake site & Rat striatum & 2.0 nM, [ [ H]WIN35,428 & $100 \mu \mathrm{M}$, cocaine & $30 \min , 4^{\circ} \mathrm{C}$ & Valchar and Hanbauer (1993) \\
\hline Serotonin $5-\mathrm{HT}_{1}$ & Rat cortex & $1.8 \mathrm{nM},\left[{ }^{3} \mathrm{H}\right]-5 \mathrm{HT}$ & $5 \mu \mathrm{M}, 5-\mathrm{HT}$ & $20 \mathrm{~min}, 37^{\circ} \mathrm{C}$ & Bennet and Snyder (1976) \\
\hline Serotonin $5-\mathrm{HT}_{2}$ & Rat prefrontal cortex & $0.6 \mathrm{nM},\left[{ }^{3} \mathrm{H}\right]$ ketanserin & $3.6 \mu \mathrm{M}$, metergoline & $20 \mathrm{~min}, 37^{\circ} \mathrm{C}$ & Leysen et al. (1981) \\
\hline Serotonin $5-\mathrm{HT}_{3}$ & Rat entorhinal cortex & $0.2 \mathrm{nM},\left[{ }^{3} \mathrm{H}\right] \mathrm{GR} 65630$ & $72 \mu \mathrm{M}$, quipazine & $30 \mathrm{~min}, 37^{\circ} \mathrm{C}$ & Kilpatrick et al. (1987) \\
\hline Serotonin uptake site & Rat forebrain & $0.04 \mathrm{nM},\left[{ }^{3} \mathrm{H}\right]$ paroxetine & $100 \mu \mathrm{M}, 5-\mathrm{HT}$ & $60 \min , 22^{\circ} \mathrm{C}$ & Marcusson et al. (1988) \\
\hline Benzodiazepines & Rat forebrain & $1 \mathrm{nM},\left[{ }^{3} \mathrm{H}\right] \mathrm{RO} 15-1788$ & $10 \mu \mathrm{M}$, diazepam & 90 min, melting ice & Chiu and Rosemberg (1983) \\
\hline $\mathrm{GABA}_{A}$ & $\begin{array}{l}\text { Rat cortex and cere- } \\
\text { bellum }\end{array}$ & $2.20 \mathrm{nM},\left[{ }^{3} \mathrm{H}\right] \mathrm{muscimol}$ & $20 \mu \mathrm{M}, \mathrm{GABA}$ & $30 \min , 4^{\circ} \mathrm{C}$ & Yoneda and Kuriyama (1980) \\
\hline $\mathrm{GABA}_{\mathrm{B}}$ & Rat cortex & $10 \mathrm{nM},\left[{ }^{3} \mathrm{H}\right] \mathrm{GABA}$ & $100 \mu \mathrm{M},(-)$ baclofen & $10 \min , 25^{\circ} \mathrm{C}$ & $\begin{array}{l}\text { Enna and Snyder (1977), Her- } \\
\text { schel and Baldessarini (1979) }\end{array}$ \\
\hline Chlorine channel & Rat whole brain & $0.11 \mathrm{nM},\left[{ }^{35} \mathrm{~S}\right] \mathrm{TBPS}$ & $100 \mu \mathrm{M}$, picrotoxinin & $120 \min , 25^{\circ} \mathrm{C}$ & Corda et al. (1993) \\
\hline AMPA & Rat cerebral cortex & $8 \mathrm{nM},\left[{ }^{3} \mathrm{H}\right] \mathrm{AMPA}$ & $1 \mathrm{mM}$, I-glutamate & $60 \min , 4^{\circ} \mathrm{C}$ & Murphy et al. (1987) \\
\hline NMDA & Rat cerebral cortex & 5 nM, [ $\left.{ }^{3} \mathrm{H}\right] \mathrm{CGP} 39653$ & $100 \mu \mathrm{M}$, I-glutamate & $60 \min , 4^{\circ} \mathrm{C}$ & Sills et al. (1991) \\
\hline Kainate & Rat cerebral cortex & $5 \mathrm{nM},\left[{ }^{3} \mathrm{H}\right]$ kainic acid & $1 \mathrm{mM}$, I-glutamate & $60 \min , 4^{\circ} \mathrm{C}$ & $\begin{array}{l}\text { Monaghan and Cotman } \\
\text { (1982) }\end{array}$ \\
\hline
\end{tabular}


0, 5, 50, and $200 \mathrm{mg} / \mathrm{kg}$ GET73, $30 \mathrm{~min}$ before exposure to the test cage. Locomotor activity was recorded for 30 consecutive min in six 5-min bins.

\section{Experiment 4: passive avoidance}

Four identical two-way shuttle boxes [Automatic Reflex Conditioner; Ugo Basile, Comerio, Italy; $55 \mathrm{~cm} \times 33 \mathrm{~cm} \times 33(\mathrm{~h}) \mathrm{cm}$ ] were used. Each box was divided into two equally sized compartments (one illuminated and one dark) and connected by a vertical sliding door. The grid floor consisted of forty 3-mm diameter, stainless-steel rods spaced $12 \mathrm{~mm}$ apart, through which a scrambled foot-shock was delivered by a programming-recording unit (Ugo Basile, Comerio, Italy).

The procedure consisted of a training and a test session. In the training session the rat was gently placed in the illuminated compartment and allowed to freely explore both compartments. Once the rat entered the dark compartment, the sliding door was closed and a $0.5 \mathrm{~mA}$ foot-shock was delivered for $2 \mathrm{~s}$. Rats not entering the dark compartment within $120 \mathrm{~s}$ were excluded. After foot-shock delivery, the rat was immediately removed from the box and returned to its homecage. The test session was carried out $24 \mathrm{~h}$ later. The sliding door was kept open and no foot-shock was delivered. Latency of entry into the dark compartment was recorded. If a rat did not enter the dark compartment within $180 \mathrm{~s}$, it was assigned the latency value of 180 .

Three independent experiments were conducted. In each experiment, rats were divided into four groups $(n=9-10)$. GET73 was administered acutely and i.p. at the doses of $0,5,10$, and $25 \mathrm{mg} / \mathrm{kg}$, $30 \mathrm{~min}$ before the training session (Experiment $4 \mathrm{a}$ ), immediately after the training session (Experiment $4 \mathrm{~b}$ ), or $30 \mathrm{~min}$ before the test session (Experiment 4c).

\section{Experiment 5: active avoidance}

The four shuttle boxes previously described (see Experiment 4) were used. Each box was equipped with white lamps and housed in a ventilated isolation cubicle $[70 \mathrm{~cm} \times 45 \mathrm{~cm} \times 50(\mathrm{~h}) \mathrm{cm}]$ for sound attenuation.

The Active Avoidance paradigm was carried out over two consecutive days. On day 1 (habituation session), each rat was placed in the box and allowed to freely explore both compartments for $50 \mathrm{~min}$. This initial session was carried out to allow rats to fully explore the box and minimize novelty-associated stress in the test session. The number of spontaneous crossings between the two compartments was recorded by the programming-recording unit. Test session (day 2) consisted of 100 avoidance trials; each trial consisted of a 12-s lights on of the white light (conditioned stimulus, $\mathrm{CS}$ ) and a 2-s, 0.5-mA foot-shock delivery (unconditioned stimulus, US). US was delivered $10 \mathrm{~s}$ after onset of CS presentation. The inter-trial interval was randomly variable (range: 25-45 s). Rat crossing had two consequences on US: (a) complete prevention, if crossing occurred within $10 \mathrm{~s}$ from onset of CS (avoidance); (b) termination, if crossing occurred once US had already been delivered (escape). If a rat failed to shuttle, the response was recorded as escape failure. Each session lasted approximately $50 \mathrm{~min}$.

On day 2, rats were divided into four groups $(n=8)$, matched for body weight and number of crossings on day 1. GET73 was administered acutely and i.p. at the doses of $0,5,10$, and $25 \mathrm{mg} / \mathrm{kg}$, 30 min before the test.

\section{Experiment 6: water maze}

The effect of GET73 on spatial memory was explored using a modified water version of the Hebb-Williams maze (Hebb and Williams, 1946; Kobayashi et al., 2002). In this spatial learning task, rats are required to learn the location of an exit from a water pool, with a fixed configuration of inner barriers, across a series of daily sessions. The latency to reach the exit and the number of errors made during the acquisition are taken as indexes of learning. Moreover, this procedure allows to assess working-memory (WM) and reference-memory (RM) capacities. Trial-specific WM allows the animal to recall zones entered previously on the current trial and therefore avoid re-entries; RM refers to stored representations and rules that are useful for all trials (Olton et al., 1979; Eichenbaum, 2001). Two custom-made, gray plastic boxes $[90 \mathrm{~cm} \times 54 \mathrm{~cm} \times 40(\mathrm{~h}) \mathrm{cm}]$, filled with warm water $\left(25^{\circ} \mathrm{C}\right)$ up to the height of $20 \mathrm{~cm}$, were used. A series of inner barriers were arranged to create the maze illustrated in Figure 2, with an entry zone (Figure 2A), a series of blind alleys (Figures 2A-E, error zones), and an exit metal grid (Figure 2F), the final portion of which was above the water level. Multiple intra-maze (e.g., black/white stripes on the wall of the exit zone) and extra-maze (e.g., lab benches and shelves) cues facilitated acquisition of the spatial map.

Each rat underwent five daily sessions (Monday to Friday). Specifically, the rat was gently placed in the entry zone and allowed to freely swim with a cut-off time of $5 \mathrm{~min}$. In the first session, if the rat failed to reach the exit zone within $5 \mathrm{~min}$, it was gently guided to the exit zone. After each session, rats were dried with paper towels and exposed to a heater before returning to the homecage.

In each session, measured variables were: (a) latency (in second) to reach the exit zone; (b) number of alley errors (i.e., entries into the blind alleys); (c) number of swimming reversals (defined as complete U-turns). Additionally, number of workingmemory errors (i.e., re-entries in blind alleys already visited in the

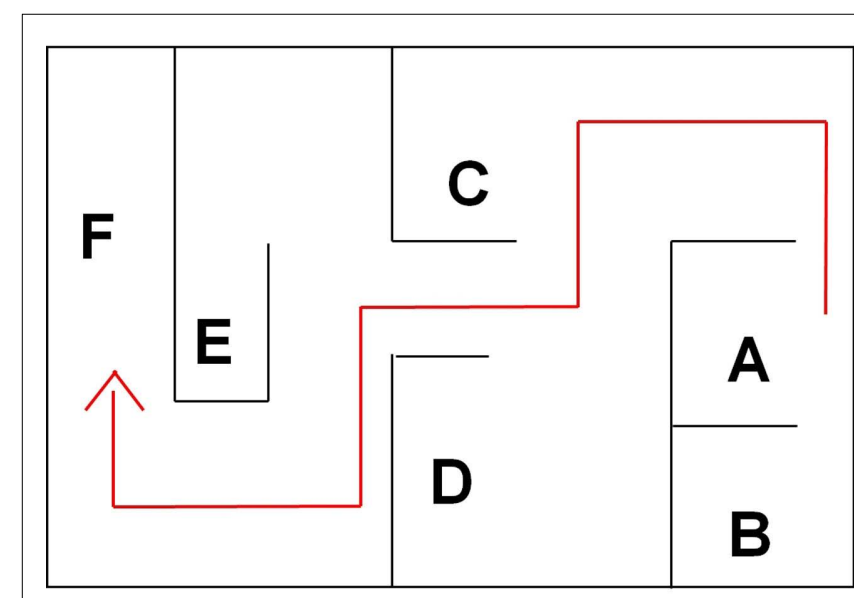

FIGURE $\mathbf{2}$ | The water maze apparatus and its different zones, coded as follows: (A) entry zone; (A-E) blind alleys (error zones); (F) exit zone. 
on-going session) and number of reference-memory errors (i.e., re-entries in blind alleys visited in the very previous session) were recorded. Tracking analysis [performed by computer-controlled, digital camera, and Smart V2.0 software (see above)] provided measures of distance traveled (in centimeter) and swimming speed (in centimeter per second).

Rats were divided into four groups $(n=10)$, matched for body weight. GET73 was administered i.p. at the doses of $0,5,10$, and $50 \mathrm{mg} / \mathrm{kg}$, $30 \mathrm{~min}$ before each daily session.

\section{Experiment 7: elevated plus maze}

The elevated plus maze (EPM) is one of the most widely used task to assess anxiety-related behaviors in rodents. This procedure involves stimuli that are ethologically relevant to rats and mice, being based on the spontaneous aversion of rodents for open, unprotected environments and their preference for sheltered, safe spaces (see Hogg, 1996; Rodgers et al., 1997). Specifically, the EPM test measures the conflict of rats and mice between the propensity to explore the open arms (OAs) of the maze and to stay in its closed arms (CAs). The validity of the EPM procedure has been further improved by addition of measurement of risk-assessment responses (see Hogg, 1996; Rodgers et al., 1997). The EPM apparatus (Med Associates, St. Albans, VT, USA) was made of black plexiglas and consisted of four arms $[12(\mathrm{w}) \mathrm{cm} \times 60(\mathrm{l}) \mathrm{cm}]$ positioned to form a plus sign. Two opposite facing arms had $50(\mathrm{~h})-\mathrm{cm}$ walls and open roof (CAs), whereas the other two opposite facing arms had no walls (OAs), unless a $0.5(\mathrm{~h})-\mathrm{cm}$ border. The arms were connected by a $12 \mathrm{~cm} \times 12 \mathrm{~cm}$ central square (CS). The entire maze was elevated $50 \mathrm{~cm}$ above the floor. A custom-made, computer-controlled, video-tracking system was used to record rat behavior.

At the start of the EPM test, each rat was placed on one of the OAs facing the CS. At the end of each test, the maze was cleaned thoroughly. During the 5-min test, the following variables were recorded: (a) number of entries into CAs (ECAs); (b) number of entries into OAs (expressed as percent of total number of entries into arms; \%EOAs); (c) time spent in OAs (expressed as percent of total time spent in arms; \%TOAs); (d) total number of stretched attend postures (SAPs; defined as the rat stretching to its full length with the forepaws, keeping the hindpaws in the same place, and then resuming the initial position); (e) number of protected SAPs (defined as those SAPs occurring in CAs); (f) number of unprotected SAPs (defined as those SAPs occurring in OAs); (g) total number of head dippings (HDs; defined as moving the head below the level of the maze floor); (h) number of protected HDs (defined as those HDs occurring in CAs); (i) number of unprotected HDs (defined as those HDs occurring in OAs); (1) number of end-arm explorations in OAs (defined as the rat reaching the last $10-\mathrm{cm}$ portion of OA). Entry into a given arm was scored once the rat had all four paws in that arm. Number of ECAs was recorded as measure of locomotor activity; \%EOAs and \%TOAs were recorded as measure of anxiety-related behaviors; SAPs, HDs, and end-arm explorations in OAs were recorded as measure of risk assessment.

Two independent experiments were conducted, one testing SD rats (Experiment $7 \mathrm{a}$ ) and one testing sP rats (Experiment $7 \mathrm{~b}$ ). In both experiments, rats were fasted $15 \mathrm{~h}$ before GET73 administration. In Experiment 7a, on the test day, rats were divided into five groups $(n=4-7)$, matched for body weight. GET73 was administered acutely and i.g. at the doses of $0,5,10,25$, and $50 \mathrm{mg} / \mathrm{kg}$, 30 min before rat exposure to the EPM. In Experiment 7b, on the test day, rats were divided into four groups $(n=12-14)$, matched for body weight. GET73 was administered acutely and i.g. at the doses of $0,10,25$, and $50 \mathrm{mg} / \mathrm{kg}, 30 \mathrm{~min}$ before rat exposure to the EPM. Rats were alcohol-naive.

\section{Experiment 8: maintenance of alcohol intake}

Rats of the sP line were exposed to the homecage, two-bottle choice regimen between alcohol $(10 \% \mathrm{v} / \mathrm{v}$, in water) and water, with unlimited access for $24 \mathrm{~h} /$ day, for eight consecutive weeks before the start of the experiment with GET73; this procedure resulted in the production of "alcohol-experienced" rats with steady daily intakes of alcohol. Bottles were refilled every day with fresh solution and their left-right positions interchanged daily to avoid development of position preference. Daily alcohol, water, and food intake was monitored by weighing the bottles and food pellets $(0.1$ g accuracy) every day immediately before the start of the dark phase.

On the test day, rats were divided into four groups $(n=10)$, matched for body weight as well as alcohol, water, and food intake during the last 7 days preceding the experiment. GET73 was administered acutely and i.g. at the doses of $0,10,25$, and $50 \mathrm{mg} / \mathrm{kg}, 30 \mathrm{~min}$ before lights off. Alcohol, water, and food intake was monitored by weighing the bottles and food pellets 60,120 , 180 , and $240 \mathrm{~min}$ after lights off.

\section{Experiment 9: alcohol deprivation effect}

The effect of GET73 on relapse-like drinking was investigated using the "alcohol deprivation effect" (ADE) test. ADE is defined as the temporary increase in alcohol intake occurring, in different animal species, after a period of abstinence from alcohol; this increase in alcohol intake has been validated as an animal model of relapse drinking episodes and loss of control over alcohol in human alcoholics (see Spanagel, 2005). Rats of the sP line constitute a proper animal model for this investigation, as they display a pronounced $\mathrm{ADE}$ during the first hour of re-access to alcohol after a period of deprivation from alcohol (see Colombo et al., 2006).

Three independent experiments, each testing a different GET73 dose-range, were conducted. Each experiment started with a 6week period during which rats were given continuous access to alcohol (10\% v/v, in water) and water under the homecage, twobottle choice regimen. Daily alcohol, water, and food intake was monitored as described above (see Experiment 8).

In each experiment, at the end of this initial period of free access to alcohol, rats were divided into two groups (matched for body weight as well as alcohol, water, and food intake over the last 7 days). One rat group was deprived of alcohol for 14 consecutive days, during which water was the sole fluid available (alcoholdeprived rats). The second rat group continued to have unlimited access to alcohol and water (alcohol-non-deprived rats), with the exception of the last $6 \mathrm{~h}$ before GET73 administration, when the alcohol bottle was removed to ensure that blood alcohol levels were equal to zero at the time of the test.

In each experiment, at the end of the 14th day of the deprivation phase, rats of both groups were divided into three subgroups, 
matched for body weight, and treated with either (a) $0 \mathrm{mg} / \mathrm{kg}$ $(n=16-17), 1.25 \mathrm{mg} / \mathrm{kg}(n=15-18)$, and $2.5 \mathrm{mg} / \mathrm{kg}(n=15-17)$ GET73 (Experiment 9a), (b) $0 \mathrm{mg} / \mathrm{kg}(n=10), 5 \mathrm{mg} / \mathrm{kg}(n=10)$, and $10 \mathrm{mg} / \mathrm{kg}(n=10)$ GET73 (Experiment 9b), or (c) $0 \mathrm{mg} / \mathrm{kg}$ $(n=7-8), 25 \mathrm{mg} / \mathrm{kg}(n=8)$, and $50 \mathrm{mg} / \mathrm{kg}(n=8)$ GET73 (Experiment 9c). GET73 was administered acutely and i.g. $30 \mathrm{~min}$ before lights off. Alcohol was presented once again at lights off. Alcohol, water, and food intake was recorded 60 min later.

\section{STATISTICAL ANALYSIS}

All data are reported as mean \pm SEM. Parametric analysis was performed using the Student's $t$-test and one- or two-way analysis of variance (ANOVA), followed by the Newman-Keuls test for post hoc comparisons. Non-parametric analysis of independent samples was carried out using the Kruskal-Wallis ANOVA or Mann-Whitney $U$-test. Non-parametric analysis of dependent samples was done by Friedman ANOVA for dependent samples.

\section{RESULTS}

\section{EXPERIMENT 1: [ $\left.{ }^{3} \mathrm{H}\right] \mathrm{GHB}$ BINDING ASSAY}

As expected from previous studies (Carai et al., 2002; Castelli et al., 2003), GHB - used as reference compound - inhibited $\left[{ }^{3} \mathrm{H}\right] \mathrm{GHB}$ binding with $\mathrm{IC}_{50}$ equal to $108 \pm 30 \mathrm{nM}$ and $3.5 \pm 1.0 \mu \mathrm{M}$ (highand low-affinity GHB recognition sites, respectively). Conversely, GET73 - tested at concentrations ranging from $10^{-9}$ to $10^{-3} \mathrm{M}-$ failed to inhibit $\left[{ }^{3} \mathrm{H}\right] \mathrm{GHB}$ binding at both $\mathrm{GHB}$ recognition sites.

\section{EXPERIMENT 2: OTHER BINDING ASSAYS}

The sole, although weak, interactions displayed by GET73 with selected receptor systems (listed in Table 1) were those with (a) 5$\mathrm{HT}_{3}$ receptor, as suggested by a $13 \%$ inhibition of $\left[{ }^{3} \mathrm{H}\right] \mathrm{GR} 65630$ binding at the concentration of $10^{-5} \mathrm{M}$ GET73, and (b) GABA receptor, as suggested by a $30 \%$ inhibition of $\left[{ }^{3} \mathrm{H}\right]$ muscimol binding at the concentration of $10^{-5} \mathrm{M}$ GET73.

\section{EXPERIMENT 3: SPONTANEOUS MOTOR ACTIVITY}

Analysis of time-course revealed that only the $200-\mathrm{mg} / \mathrm{kg}$ dose of GET73 affected spontaneous locomotor activity in $\mathrm{SD}$ rats $\left[F_{\text {treatment }}(3,28)=4.89, P<0.01 ; F_{\text {time }}(5,140)=85.16\right.$, $P<0.0001 ; F_{\text {interaction }}(15,140)=1.26, P>0.05$; Figure 3$]$. Distance traveled by $200-\mathrm{mg} / \mathrm{kg}$ GET73-treated rats was indeed 15$25 \%$ lower than that recorded in vehicle-treated rats at 5-, 10-, 15-, and 20-min time intervals (Figure 3). Conversely, distance traveled was totally unaltered, at any time interval, by treatment with 5 and $50 \mathrm{mg} / \mathrm{kg}$ GET73 (Figure 3).

Total distance traveled over the entire 30-min session was affected by treatment with GET73 $[F(3,28)=4.894, P<0.05]$. Post hoc analysis revealed a difference between 0 and $200 \mathrm{mg} / \mathrm{kg}$ GET73-treated rat groups $(P<0.05$, Newman-Keuls test; Figure 3, inset).

\section{EXPERIMENT 4: PASSIVE AVOIDANCE}

During the training session (day 1) of all three experiments, rats entered the dark compartment with a relatively short latency $(<50 \mathrm{~s})$ and no difference among rat groups [Experiment $4 \mathrm{a}$ : $F(3,34)=1.99, P>0.05$; Experiment 4b: $F(3,35)=0.57, P>0.05$; Experiment 4c: $F(3,36)=1.53, P>0.05$; Table 2].

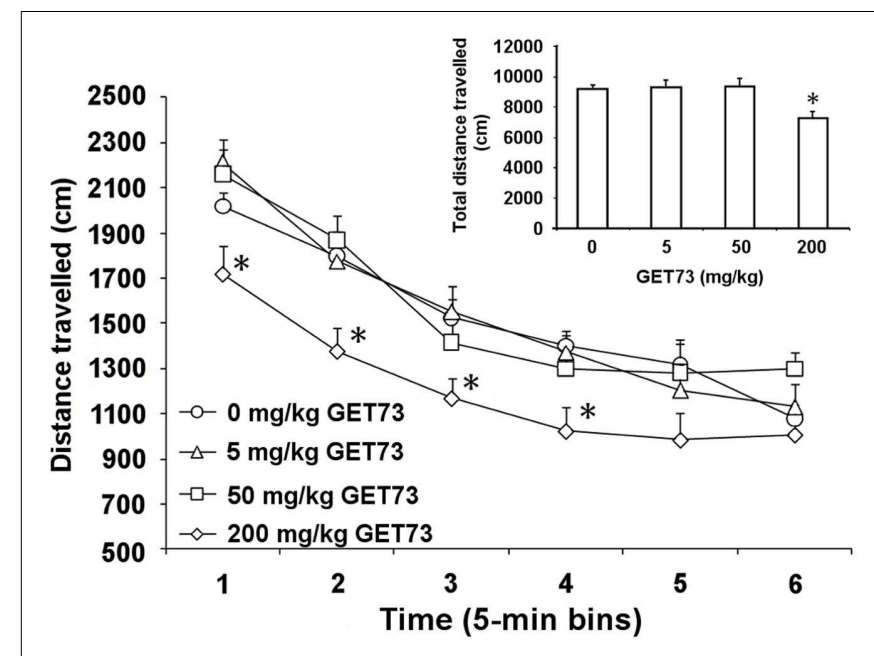

FIGURE 3 | Effect of the acute, intragastric administration of different doses of GET73 on spontaneous locomotor activity in

Sprague-Dawley rats. GET73 was administered 30 min before the start of the 30-min session. Data were recorded in six 5-min bins; total distance traveled over the 30-min session is reported in the inset. Each point or bar is the mean \pm SEM of $n=8$. ${ }^{*} P<0.05$ with respect to $0-\mathrm{mg} / \mathrm{kg}$

GET73-treated rat group at the corresponding time (Newman-Keuls test).

At the time of the test session (day 2) of all three experiments, acute treatment with GET73 did not alter the latency of entry into the dark compartment [Experiment 4a: $F(3,34)=0.0$, $P>0.05$; Experiment 4b: $F(3,35)=1.24, P>0.05$; Experiment $4 \mathrm{c}$ : $F(3,36)=0.19, P>0.05$; Table 2]. These data suggest that treatment with GET73 did not alter the rats' performance at the Passive Avoidance test, irrespective of the time of GET73 administration [ 30 min before the training session (Experiment $4 \mathrm{a}$ ), immediately after the training session (Experiment $4 \mathrm{~b}$ ), or $30 \mathrm{~min}$ before the test session (Experiment 4c)].

\section{EXPERIMENT 5: ACTIVE AVOIDANCE}

Throughout the habituation session (day 1), the number of crossings did not differ among the four rat groups investigated $[F(3,28)=2.6, P>0.05$; Table 3]

In the test session (day 2), no dose of acutely administered GET73 affected any of the measured variables [number of avoidances; $F(3,28)=0.96, P>0.05$; number of escapes: $F(3,28)=0.19, P>0.05$; number of escape failures $F(3,28)=0.94$, $P>0.05$; Table 3]. These data suggest that treatment with GET73 did not alter the rats' performance at the Active Avoidance test.

\section{EXPERIMENT 6: WATER MAZE}

In vehicle-treated rats, the rats' performance tended to improve on continuing exposure to the maze task, as revealed by progressively lower values in each measured variable from day 1 to day 5 (Figure 4).

Latency in reaching the exit was not altered by repeated treatment with GET73 ( $P>0.05$, Kruskal-Wallis test; data not shown). In contrast, treatment with GET73 affected the number of alley errors (Figure 4A), number of swimming reversals (Figure 4B), 
Table 2 | Effect of the acute, intraperitoneal administration of different doses of GET73 on latency of entry into the dark compartment in training and test sessions in Sprague-Dawley rats exposed to the Passive Avoidance test.

\section{GET73 (mg/kg)}

\begin{tabular}{llll}
\hline 0 & 5 & 10 & 25
\end{tabular}

\begin{tabular}{lllc}
\hline EXPERIMENT 4a & & & \\
Training session (day 1) & $15.2 \pm 4.1$ & $10.1 \pm 3.5$ & $21.6 \pm 4.0$ \\
Test session (day 2) & $180.0 \pm 0.0$ & $180.0 \pm 0.0$ & $180.0 \pm 0.0$ \\
EXPERIMENT 4b & & & $7.8 \pm 2.0$ \\
Training session (day 1) & $11.5 \pm 2.9$ & $8.5 \pm 1.8$ & $180.0 \pm 0.0$ \\
Test session (day 2) & $180.0 \pm 0.0$ & $162.8 \pm 17.2$ & $8.0 \pm 2.0$ \\
EXPERIMENT 4c & & & $8.5 \pm 2.1$ \\
Training session (day 1) & $12.4 \pm 2.7$ & $13.9 \pm 3.6$ & $162.1 \pm 17.9$ \\
Test session (day 2) & $146.9 \pm 22.1$ & $162.1 \pm 17.9$ & $6.8 \pm 2.0$ \\
\end{tabular}

GET73 was administered acutely 30 min before the training session (Experiment 4a), immediately after the training session (Experiment $4 b$ ), or 30 min before the test session (Experiment 4c). Each value is the mean \pm SEM of $n=9-10$.

Table 3 | Effect of the acute, intraperitoneal administration of different doses of GET73 on a series of variables measured in habituation and test sessions in Sprague-Dawley rats exposed to the Active Avoidance test.

\begin{tabular}{lllll}
\hline $\mathbf{G E T 7 3}(\mathbf{m g} / \mathbf{k g})$ & Habituation session (day 1) & \multicolumn{2}{c}{ Test session (day 2) } \\
\cline { 3 - 5 } & Number of crossings & Number of avoidances & Number of escapes & Number of escape failures \\
\hline 0 & $54.5 \pm 7.2$ & $57.9 \pm 3.1$ & $31.3 \pm 3.8$ & $10.9 \pm 2.2$ \\
5 & $62.6 \pm 9.6$ & $38.3 \pm 10.1$ & $31.9 \pm 5.9$ & $29.9 \pm 11.9$ \\
10 & $83.1 \pm 4.3$ & $50.6 \pm 9.5$ & $28.4 \pm 4.3$ & $21.0 \pm 7.1$ \\
25 & $62.9 \pm 8.1$ & $47.3 \pm 8.7$ & $33.5 \pm 5.1$ & $19.3 \pm 7.9$ \\
\hline
\end{tabular}

GET73 was administered acutely 30 min before the test session. Each value is the mean $\pm S E M$ of $n=8$.

and number of working-memory errors (Figure 4C) in a relatively complex manner.

Specifically, treatment with $5 \mathrm{mg} / \mathrm{kg}$ GET73 (a) had no effect on the number of alley errors (Figure 4A), (b) marginally affected the number of swimming reversals in session $5(P=0.091)$, and (c) reduced the number of working-memory errors in session 5 $(P<0.05$, Kruskal-Wallis and Mann-Whitney test; Figure 4C). Treatment with $10 \mathrm{mg} / \mathrm{kg}$ GET73 (a) had no effect on the number of alley errors (Figure 4A), (b) reduced the number of swimming reversals in session 5 ( $P<0.01$, Mann-Whitney test; Figure 4B), and (c) reduced the number of working-memory errors in session $2(P<0.05$, Kruskal-Wallis and Mann-Whitney test; Figure 4C). Conversely, treatment with $50 \mathrm{mg} / \mathrm{kg}$ GET73 increased the number of (a) alley errors in session $1(P<0.01$, Mann-Whitney test; Figure 4A) with a marginally significant effect in session $2(P=0.053$, Mann-Whitney test $)$, (b) swimming reversals in session $1(P<0.001$, Mann-Whitney test; Figure 4B), and $(\mathrm{c})$ working-memory errors in session $1(P<0.01$, Mann-Whitney test), with a marginally significant effect in session $2(P=0.080$, Mann-Whitney test; Figure 4C). Finally, no dose of GET73 altered the number of reference-memory errors (data not shown).

In line with the complex profile illustrated above, GET73 altered the distance traveled to reach the exit in sessions 1 and $5(P<0.01$ and $P<0.05$, respectively, Kruskal-Wallis test), with marginally significant effects in sessions $3(P=0.065$, Kruskal-Wallis test $)$ and $4(P=0.086$, Kruskal-Wallis test $)$. Specifically, treatment with 5 and $10 \mathrm{mg} / \mathrm{kg}$ GET73 decreased the distance traveled in session 5 $(P<0.05$, Mann-Whitney test; Figure 4D); conversely, treatment with $50 \mathrm{mg} / \mathrm{kg}$ GET73 increased the distance traveled in session 1 $(P<0.01$, Mann-Whitney test; Figure 4D).

Mean speed of swimming was not altered by GET73 treatment, ruling out a possible motor dysfunction $(P>0.05$, Kruskal-Wallis test; data not shown).

\section{EXPERIMENT 7: ELEVATED PLUS MAZE}

In Experiment 7a (SD rats), acute treatment with GET73 did not alter basal locomotor activity, as revealed by the lack of any difference in the number of ECAs among the five rat groups $(P>0.05$, Kruskal-Wallis test; Table 4). Treatment with GET73 exerted an anxiolytic effect, as indicated by the increase - with respect to vehicle-treated rats - in \%EOAs $(P<0.05$, Kruskal-Wallis test; Figure 5A $)$ and \%TOAs $(P<0.05$, Kruskal-Wallis test; Figure 5B). The increase in \%EOAs occurred at the doses of 25 and $50 \mathrm{mg} / \mathrm{kg}$ $(P<0.01$, Mann-Whitney test $)$, while the increase in \%TOAs occurred at the doses of 10 ( $P<0.05$, Mann-Whitney test), 25 $(P<0.01$, Mann-Whitney test $)$, and $50 \mathrm{mg} / \mathrm{kg}(P<0.01$, MannWhitney test). Treatment with GET73 decreased total number of SAPs $(P<0.01$, Kruskal-Wallis test $)$ and number of protected 

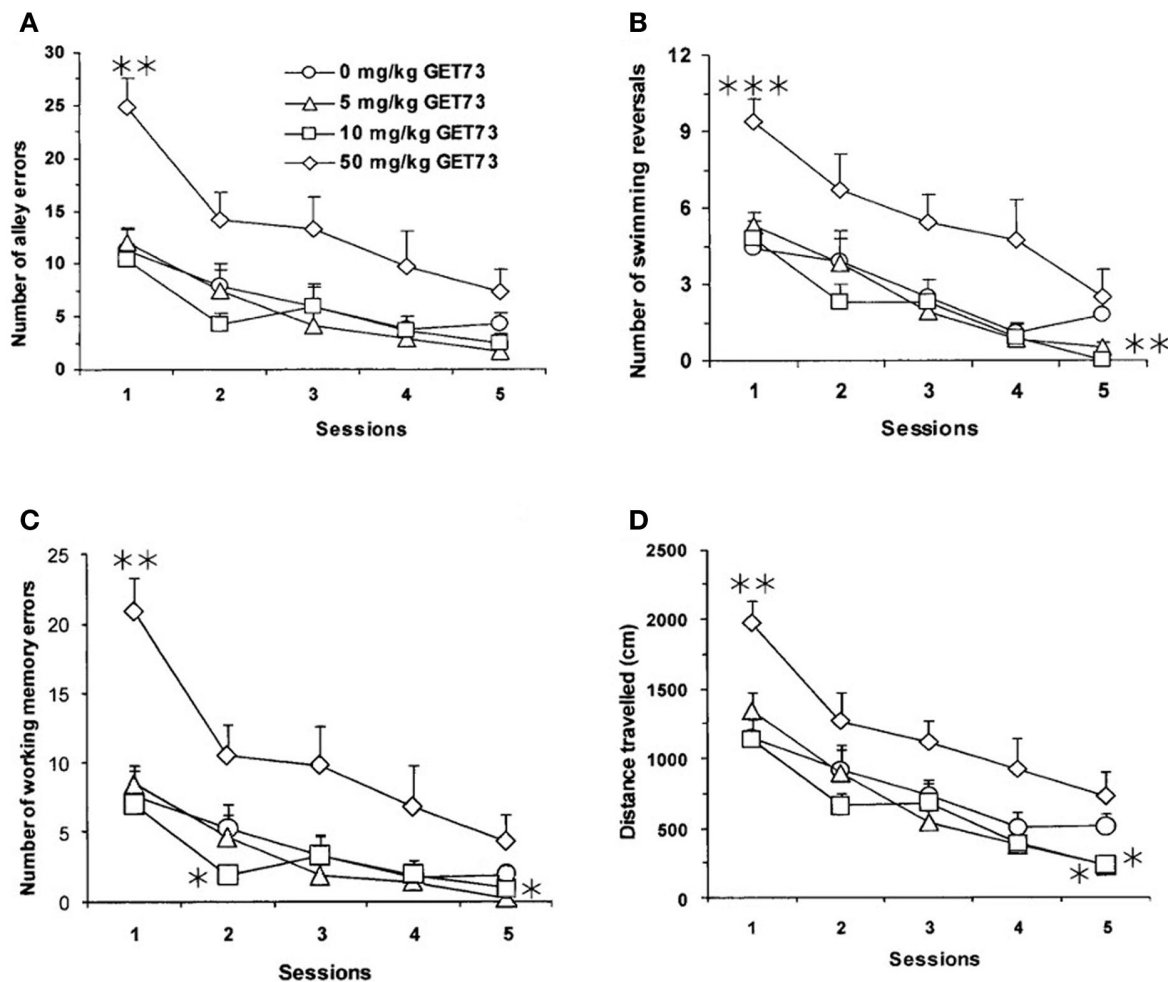

FIGURE 4 | Effect of the repeated, intraperitoneal administration of different doses of GET73 on three measures of spatial memory in Sprague-Dawley rats exposed to the water maze (WM) test: number of alley errors [entries into blind alleys (A)], number of swimming reversals [defined as complete U-turns (B)], number of working-memory errors [re-entries in blind alleys already visited in

the on-going session (C)], and distance traveled [in cm; (D)]. GET73 was administered $\mathbf{3 0}$ min before each WM session. Each WM session lasted for $5 \mathrm{~min}$. Each point is the mean \pm SEM of $n=10$. ${ }^{*} P<0.05$, ${ }^{*} P<0.01$, and ${ }^{*}{ }^{*} P<0.001$ with respect to 0 -mg/kg GET73-treated rat group in the corresponding session (Kruskal-Wallis and Mann-Whitney test).

Table 4 | Effect of the acute, intragastric administration of different doses of GET73 on a series of variables measured in Sprague-Dawley rats exposed to the elevated plus maze (EPM) test.

\section{GET73 (mg/kg)}

\begin{tabular}{lllll}
\hline $\mathbf{0}$ & $\mathbf{5}$ & $\mathbf{1 0}$ & $\mathbf{2 5}$ & $\mathbf{5 0}$ \\
\hline $6.3 \pm 1.1$ & $7.7 \pm 1.1$ & $7.0 \pm 0.3$ & $6.0 \pm 0.9$ & $8.2 \pm 1.7$ \\
$6.3 \pm 1.4$ & $3.8 \pm 0.9$ & $4.0 \pm 0.9$ & $1.0 \pm 0.7^{*}$ & $1.2 \pm 0.4^{* *}$ \\
$5.7 \pm 1.2$ & $3.2 \pm 0.4$ & $3.8 \pm 0.9$ & $1.0 \pm 0.7^{*}$ & $1.2 \pm 0.4^{* *}$ \\
$0.6 \pm 0.4$ & $0.6 \pm 0.6$ & $0.2 \pm 0.2$ & $0.0 \pm 0.0$ & $0.0 \pm 0.0$ \\
$8.6 \pm 1.3$ & $11.6 \pm 2.7$ & $17.0 \pm 2.9$ & $15.5 \pm 3.8$ & $11.6 \pm 1.9$ \\
$6.9 \pm 1.1$ & $4.4 \pm 1.0$ & $6.0 \pm 1.4$ & $8.0 \pm 2.3$ & $5.6 \pm 1.7$ \\
$1.7 \pm 0.7$ & $7.2 \pm 3.0$ & $11.0 \pm 3.0^{* *}$ & $7.5 \pm 1.9^{*}$ & $6.0 \pm 0.4^{* *}$ \\
$0.3 \pm 0.3$ & $2.2 \pm 1.4$ & $4.8 \pm 1.7^{* *}$ & $5.5 \pm 0.3^{* *}$ & $5.0 \pm 0.8^{* *}$ \\
\hline
\end{tabular}

CA, closed arm; OA, open arm; ECAs, entries into CAs; SAPs, stretched attend postures; HDs, head dippings.

Stretched attend postures were defined as the rat's stretching to its full length with the forepaws, keeping the hindpaws in the same place, and then resuming the initial position. Protected SAPS were defined as those SAPS occurring in the CAs. Unprotected SAPS were defined as those SAPS occurring in the OAs. HDs were defined as moving the head below the level of the maze floor. Protected HDs were defined as those HDs occurring in the CAs. Unprotected HDs were defined as those HDs occurring in the OAs. End-arm explorations in OAs were defined as the rat reaching the last 10-cm portion of the open arm.

GET73 was administered acutely 30 min before the EPM test. Exposure to the EPM lasted for 5 min. Entry into a given arm was scored once the rat had all four paws in that arm. Each value is the mean \pm SEM of $n=4-7 .{ }^{*} P<0.05$ and ${ }^{*} P<0.01$ with respect to $0-\mathrm{mg} / \mathrm{kg}$ GET73-treated rat group (Kruskal-Wallis and Mann-Whitney test). 
SAPs $(P<0.01$, Kruskal-Wallis test; Table 4$)$; conversely, treatment with GET73 did not alter the number of unprotected SAPs $(P>0.05$, Kruskal-Wallis test; Table 4). The decrease in SAPs occurred at the doses of $25(P<0.05$, Mann-Whitney test $)$ and $50 \mathrm{mg} / \mathrm{kg}(P<0.01$, Mann-Whitney test $)$. Treatment with GET73 increased the number of unprotected HDs $(P<0.05$, KruskalWallis test) and end-arm explorations in OAs $(P<0.01$, KruskalWallis test; Table 4). These effects were exerted at the doses of $10(P<0.01$ for both unprotected HDs and end-arm explorations; Mann-Whitney test), $25 \mathrm{mg} / \mathrm{kg}(P<0.05$ and $P<0.01$ for unprotected HDs and end-arm explorations, respectively; MannWhitney test), and $50 \mathrm{mg} / \mathrm{kg}(P<0.01$ for both unprotected HDs and end-arm explorations; Mann-Whitney test).

In Experiment 7b ( $\mathrm{PP}$ rats), acute treatment with GET73 did not alter basal locomotor activity, as revealed by the lack of any difference in the number of ECAs among the four rat groups $[F(3,47)=0.31, P>0.05$; Table 5]. Treatment with GET73 exerted an anxiolytic effect, as indicated by the increase - with respect to vehicle-treated rats - in $\%$ EOAs $[F(3,47)=5.81, P<0.005$; Figure 6A $]$ and \%TOAs $[F(3,47)=3.55, P<0.05$; Figure 6B $]$. The anxiolytic effect of GET73 was a bell-shaped function of GET73 dose, as the increase in \%EOAs and \%TOAs occurred only at the doses of 10 and $25 \mathrm{mg} / \mathrm{kg}$ GET73. Post hoc analysis revealed an effect of both doses on \%EOAs $(P<0.05$ and $P<0.01$ for the $10-$ and $25-\mathrm{mg} / \mathrm{kg}$ GET73-treated rat groups, respectively; Newman-Keuls test) and a tendency for the 25$\mathrm{mg} / \mathrm{kg}$ GET73 dose on \%TOAs $(P=0.055$, Newman-Keuls test). ANOVA failed to reveal any difference among the 4 rat groups in (a) total number of SAPs $[F(3,47)=0.26, P>0.05]$, (b) number of protected SAPs $[F(3,47)=1.68, P>0.05]$, and (c) number of unprotected SAPs $[F(3,47)=0.25, \quad P>0.05$; Table 5]. Treatment with GET73 increased (a) total number of HDs $[F(3,47)=3.74, P<0.05]$ and (b) number of unprotected HDs $[F(3,47)=3.33, P<0.05]$; this effect was again a bell-shaped function of GET73 dose, with the 25-mg/kg GET73 dose exerting the maximal effect (Table 5). Conversely, treatment with $25 \mathrm{mg} / \mathrm{kg}$ GET73 produced only a tendency toward an increase in the number of protected HDs $[F(3,47)=1.26$, $P>0.05$; Table 5]. Finally, treatment with GET73 increased the number of end-arm explorations in OAs $[F(3,47)=3.05$, $P<0.05$; Table 5]. Again, the increase appeared to be limited to the $25-\mathrm{mg} / \mathrm{kg}$ GET73 dose $(P=0.056$, Newman-Keuls test).

\section{EXPERIMENT 8: MAINTENANCE OF ALCOHOL INTAKE}

Acute administration of 10,25, and $50 \mathrm{mg} / \mathrm{kg}$ GET73 reduced alcohol intake in alcohol-experienced $\mathrm{sP}$ rats over the first $3 \mathrm{~h}$ of the dark phase of the light/dark cycle [results of one-way ANOVA: $0-60$ min interval: $F(3,36)=7.75, P<0.0005 ; 0-120$ min interval: $F(3,36)=6.41, P<0.001 ; 0-180 \mathrm{~min}$ interval: $F(3,36)=4.46$, $P<0.01]$. This effect tended to be dose-independent, as the magnitude of the reduction in alcohol intake (with respect to vehicletreated rats) was similar among the rat groups treated with the three different doses of GET73 (Figures 7A-C). At the 0- to 60-min interval, reduction in alcohol intake (with respect to vehicletreated rats) averaged 35-45\% in GET73-treated rat groups. The reducing effect of GET73 on alcohol intake tended to vanish at the final recording time, as indicated by the lack of statistical significance at the 0 - to 240 -min interval $[F(3,36)=1.94, P>0.05$; Figure 7D].

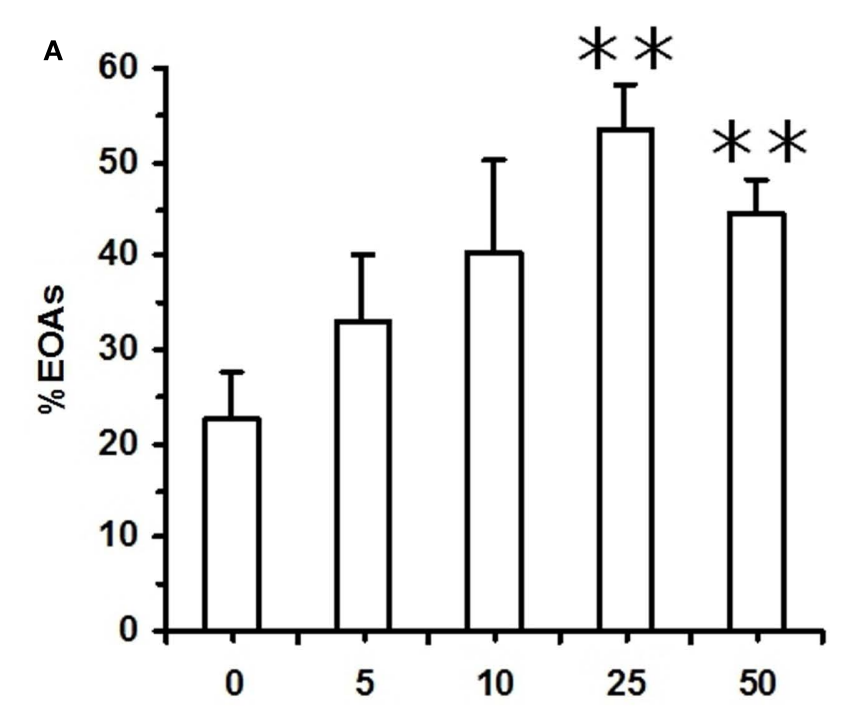

FIGURE 5 | Effect of the acute, intragastric administration of different doses of GET73 on two measures of "anxiety" [number of entries into open arms (OAs; \%EOAs; expressed as percent of total number of entries into arms (A))]; time spent in OAs [(\%TOAs; expressed as percent of total time spent in arms (B)] in Sprague-Dawley rats exposed to the elevated

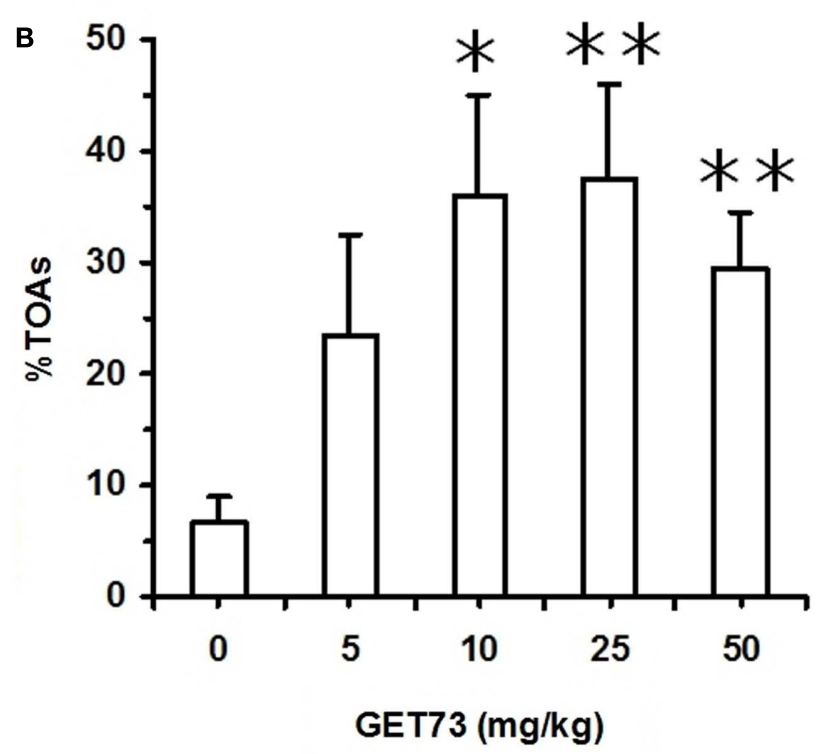

plus maze (EPM) test. GET73 was administered 30 min before the EPM test. Exposure to the EPM lasted for $5 \mathrm{~min}$. Entry into a given arm was scored once the rat had all four paws in that arm. Each bar is the mean \pm SEM of $n=4-7$. ${ }^{*} P<0.05$ and ${ }^{*}{ }^{*} P<0.01$ with respect to $0-\mathrm{mg} / \mathrm{kg}$ GET73-treated rat group (Kruskal-Wallis and Mann-Whitney test). 
Table 5 | Effect of the acute, intragastric administration of different doses of GET73 on a series of variables measured in Sardinian alcohol-preferring (sP) rats exposed to the elevated plus maze (EPM) test.

\section{GET73 $(\mathrm{mg} / \mathrm{kg})$}

\begin{tabular}{|c|c|c|c|c|}
\hline & \\
\hline & 0 & 10 & 25 & 50 \\
\hline Number of ECAs & $4.9 \pm 0.7$ & $5.5 \pm 0.8$ & $5.8 \pm 0.6$ & $5.9 \pm 0.9$ \\
\hline Total number of SAPs & $8.2 \pm 0.9$ & $7.8 \pm 1.0$ & $8.8 \pm 1.0$ & $8.0 \pm 0.6$ \\
\hline Number of unprotected SAPs & $4.8 \pm 1.0$ & $5.6 \pm 1.0$ & $4.8 \pm 0.7$ & $5.3 \pm 0.5$ \\
\hline Total number of HDs & $3.5 \pm 0.9$ & $6.8 \pm 2.0$ & $8.7 \pm 1.9 *$ & $2.8 \pm 0.6$ \\
\hline Number of end-arm explorations in OAs & $0.2 \pm 0.1$ & $0.7 \pm 0.4$ & $1.4 \pm 0.5^{*}$ & $0.2 \pm 0.1$ \\
\hline
\end{tabular}

CA, closed arm; OA, open arm; ECAs, entries into CAs; SAPs, stretched attend postures; HDs, head dippings.

Stretched attend postures were defined as the rat's stretching to its full length with the forepaws, keeping the hindpaws in the same place, and then turning back to the initial position. Protected SAPS were defined as those SAPS occurring in the CAs. Unprotected SAPS were defined as those SAPS occurring in the OAs. HDs were defined as moving the head below the level of the maze floor. Protected HDs were defined as those HDs occurring in the CAs. Unprotected HDs were defined as those HDs occurring in the OAs. End-arm explorations in OAs were defined as the rat reaching the last 10-cm portion of the open arm.

GET73 was administered acutely 30 min before the EPM test. Exposure to the EPM lasted for 5 min. Entry into a given arm was scored once the rat had all four paws in that arm. Each value is the mean $\pm S E M$ of $n=12-14 .{ }^{*} P<0.05$ with respect to $0-\mathrm{mg} / \mathrm{kg}$ GET73-treated rat group (Newman-Keuls test).

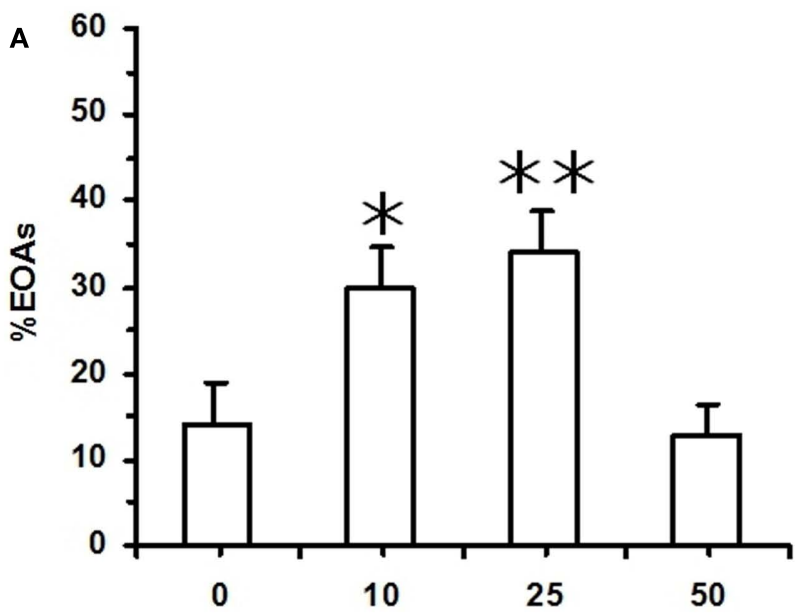

FIGURE 6 | Effect of the acute, intragastric administration of different doses of GET73 on two measures of "anxiety" [number of entries into open arms (OAs; \%EOAs; expressed as percent of total number of entries into arms (A))]; time spent in OAs [(\%TOAs; expressed as percent of total time spent in arms (B)] in Sardinian alcohol-preferring (sP) rats exposed

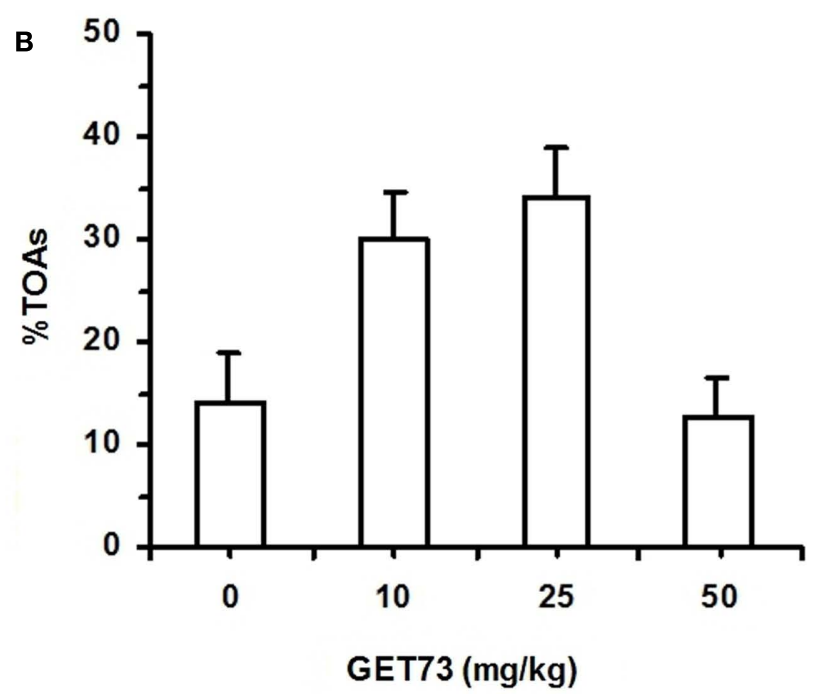

to the elevated plus maze (EPM) test. GET73 was administered $30 \mathrm{~min}$ before the EPM test. Exposure to the EPM lasted for $5 \mathrm{~min}$. Entry into a given arm was scored once the rat had all four paws in that arm. Each bar is the mean \pm SEM of $n=12-14$. ${ }^{*} P<0.05$ and ${ }^{*} P<0.01$ with respect to $0-\mathrm{mg} / \mathrm{kg}$ GET73-treated rat group (Newman-Keuls test).
Conversely, both water [results of one-way ANOVA: 0-60 min interval: $F(3,36)=0.83, P>0.05 ; 0-120$ min interval: $F(3,36)=0.73$ $P>0.05$; 0-180 min interval: $F(3,36)=0.18, P>0.05 ; 0-240 \mathrm{~min}$ interval: $F(3,36)=1.94, P>0.05$; Figures $7 \mathbf{E}-\mathbf{H}$ ] and food [results of one-way ANOVA: 0-60 min interval: $F(3,36)=0.47, P>0.05$; $0-120$ min interval: $F(3,36)=1.19, P>0.05 ; 0-180 \mathrm{~min}$ interval: $F(3,36)=0.25, \quad P>0.05 ; 0-240 \mathrm{~min}$ interval: $F(3,36)=0.49$, $P>0.05$; Figures 7I-L] intake was unaltered by treatment with GET73 at any time interval.

\section{EXPERIMENT 9: ALCOHOL DEPRIVATION EFFECT}

In Experiment 9a [testing acutely administered low doses of GET73 (1.25 and $2.5 \mathrm{mg} / \mathrm{kg}$ )], two-way (deprivation; treatment) ANOVA revealed a significant effect of deprivation alone $[F(1,92)=36.92, \quad P<0.0001]$, but not of treatment $[F(2,92)=0.15, \quad P>0.05], \quad$ and no significant interaction $[F(2,92)=0.10, P>0.05]$ on alcohol intake. In the first hour of the post-deprivation phase, alcohol intake was higher - by approximately $65 \%$ - in vehicle-treated lcohol-deprived rats 
than in vehicle-treated alcohol-non-deprived rats (Figure 8A), indicative of the development of ADE. No dose of GET73 altered, even minimally, this extra-intake of alcohol. Finally, neither water nor food intake resulted to be affected by either deprivation or treatment with GET73 [water intake: $F_{\text {deprivation }}(1,92)=0.35, P>0.05 ; F_{\text {treatment }}(2,92)=1.82$, $P>0.05 ; F_{\text {interaction }}(2,92)=2.38, P>0.05$; food intake: $F_{\text {deprivation }}$ $(1,92)=0.01, P>0.05 ; F_{\text {treatment }}(2,92)=0.10, P>0.05 ; F_{\text {interaction }}$ $(2,92)=0.02, P>0.05$; data not shown].

In Experiment $9 \mathrm{~b}$ [testing acutely administered moderate doses of GET73 (5 and $10 \mathrm{mg} / \mathrm{kg}$ )], two-way (deprivation; treatment) ANOVA revealed significant effects of treatment $[F(1,54)=4.34$, $P<0.05]$ and deprivation $[F(2,54)=7.80, P<0.005]$, and a significant interaction $[F(2,54)=6.10, P<0.005]$ on alcohol intake. In the first hour of the post-deprivation phase, alcohol intake was higher - by approximately $65 \%$ - in vehicletreated alcohol-deprived rats than in vehicle-treated alcoholnon-deprived rats (Figure $\mathbf{8 B}$ ). Post hoc analysis showed that both doses of GET73 completely suppressed this extraintake of alcohol; indeed, alcohol intake in the two GET73treated alcohol-deprived rat groups was significantly lower than that recorded in vehicle-treated alcohol-deprived rats. Further, alcohol intake did not differ between alcohol-deprived and non-deprived rats at each GET73 dose. Finally, neither water $\left[F_{\text {deprivation }}(1,54)=0.04, P>0.05 ; F_{\text {treatment }}(2,54)=0.05\right.$, $\left.P>0.05 ; F_{\text {interaction }}(2,54)=0.08, P>0.05\right]$ nor food $\left[F_{\text {deprivation }}\right.$ $(1,54)=0.01, P>0.05 ; F_{\text {treatment }}(2,54)=0.06, P>0.05 ; F_{\text {interaction }}$ $(2,54)=0.03, P>0.05]$ intake resulted to be affected by either deprivation or treatment with GET73 (data not shown).

In Experiment 9c [testing acutely administered relatively high doses of GET73 (25 and $50 \mathrm{mg} / \mathrm{kg}$ )], two-way (deprivation; treatment) ANOVA revealed a significant effect of treatment $[F(2,41)=3.56, \quad P<0.05]$, but not of deprivation $[F(1,41)=2.25, \quad P>0.05]$, and a significant interaction $[F(2,41)=4.45, P<0.05]$ on alcohol intake. In the first hour of the post-deprivation phase, alcohol intake was higher - by approximately $80 \%$ - in vehicle-treated alcohol-deprived rats than in vehicle-treated alcohol-nondeprived rats (Figure 8C). Post hoc analysis showed that both doses of GET73 completely suppressed this extraintake of alcohol; indeed, alcohol intake in the two GET73treated alcohol-deprived rat groups was lower than that

\section{$60 \mathrm{~min}$ after lights off}

A
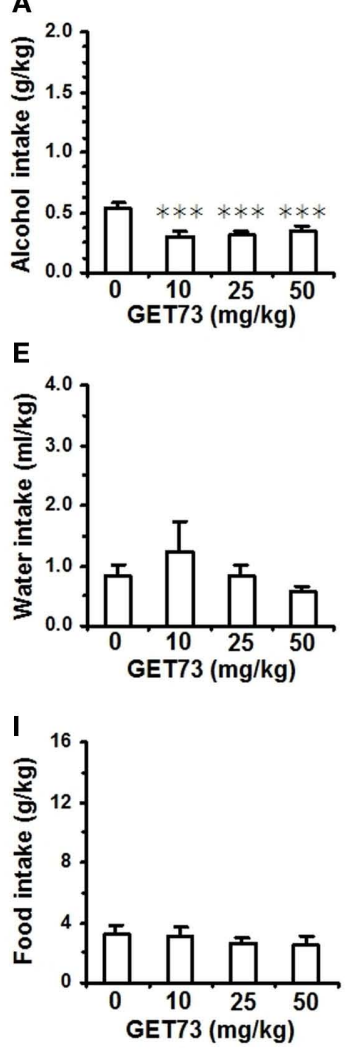

120 min after lights off

B

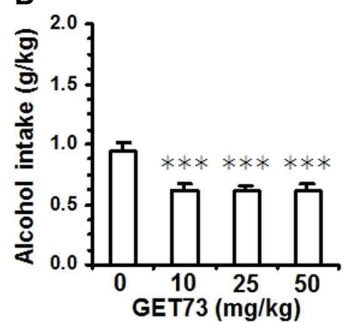

$\mathbf{F}$
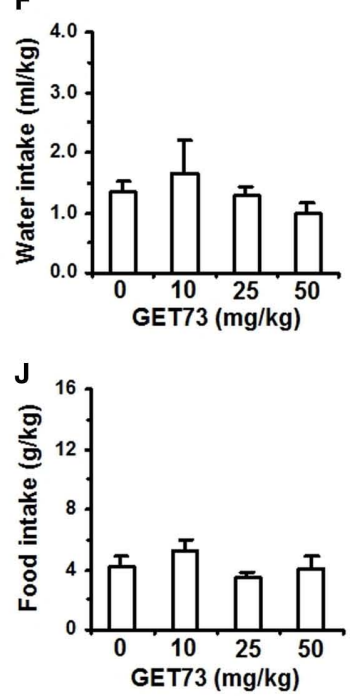

$180 \mathrm{~min}$ after lights off

C

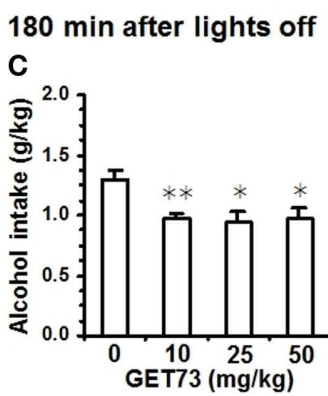

G
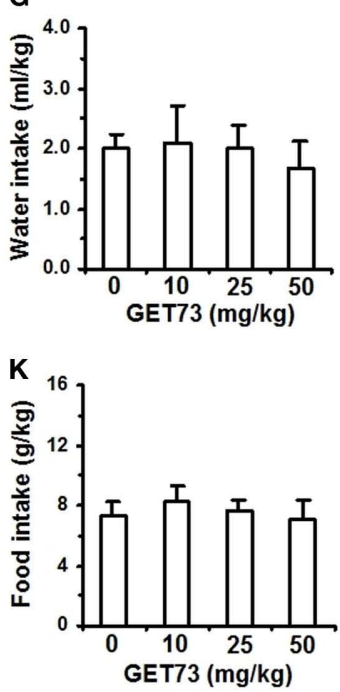
group (Newman-Keuls test).
240 min after lights off

D

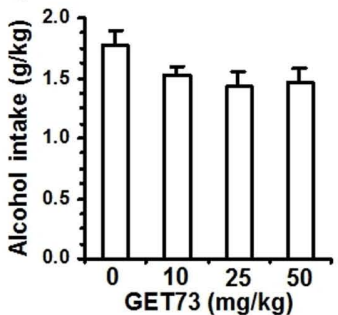

H
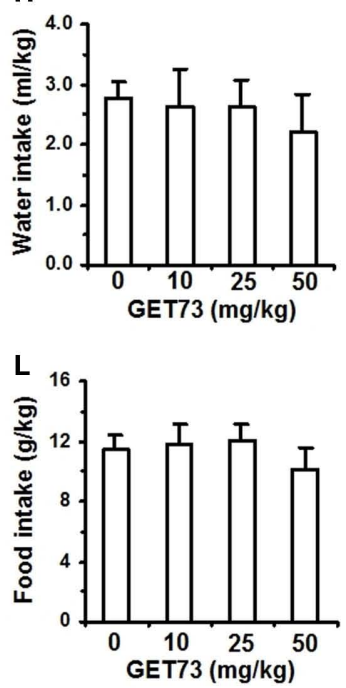

FIGURE 7 | Effect of the acute, intragastric administration of different doses of GET73 on alcohol (A-D), water (E-H), and food (I-L) intake in "alcohol-experienced" Sardinian alcohol-preferring (sP) rats. Alcohol (10\% v/v, in water) was offered under the standard, homecage two-bottle "alcohol vs water" choice regimen with unlimited

access for $24 \mathrm{~h} /$ day. GET73 was administered $30 \mathrm{~min}$ before lights off. Alcohol, water, and food intake was recorded 60, 120, 180, and $240 \mathrm{~min}$ after lights off. Each bar is the mean \pm SEM of $n=10$ rats. ${ }^{*} P<0.05$, ${ }^{*} P<0.01$, and ${ }^{* *} P<0.005$ with respect to $0-\mathrm{mg} / \mathrm{kg}$ GET73-treated rat 
recorded in vehicle-treated alcohol-deprived rats. Further, at each GET73 dose, alcohol intake did not differ significantly between alcohol-deprived and -non-deprived rats. Finally, neither water $\left[F_{\text {deprivation }}(1,41)=0.22, P>0.05 ; F_{\text {treatment }}(2,41)=1.81\right.$, $\left.P>0.05 ; F_{\text {interaction }}(2,41)=0.69, P>0.05\right]$ nor food $\left[F_{\text {deprivation }}\right.$ $(1,41)=2.27, P>0.05 ; F_{\text {treatment }}(2,41)=0.87, P>0.05 ; F_{\text {interaction }}$ $(2,41)=1.44, \quad P>0.05$ ] intake resulted to be affected by either deprivation or treatment with GET73 (data not shown).

\section{DISCUSSION}

The results of the present study illustrate how the pharmacological profile of GET73 is composed of different actions of potential interest: low-to-moderate doses of GET73 indeed exerted anti-alcohol and anxiolytic effects in multiple experimental procedures validated for the evaluation of alcohol drinking, relapse-like drinking, and anxiety-related behaviors.

Experiments 8 and 9 assessed the effect of acute administration of GET73 on different aspects of alcohol drinking in alcoholpreferring sP rats, one of the few rat lines selectively bred worldwide for high alcohol preference and consumption (see Colombo et al., 2006). The results of Experiment 8 demonstrated that doses of GET73 ranging from 10 to $50 \mathrm{mg} / \mathrm{kg}$ markedly decreased alcohol intake in alcohol-experienced sP rats, an experimental procedure thought to model the "active drinking phase" of human alcoholism (see Colombo et al., 2006). The decreasing effect of GET73 on alcohol intake appeared to be relatively dose-independent, posing the question as to its minimally effective dose(s). A subsequent series of experiments (still preliminary at the present stage) suggests that the minimally effective dose of GET73 on alcohol intake in alcohol-experienced sP rats may lie between 5 and $10 \mathrm{mg} / \mathrm{kg}$ (data not shown).

Overall results of ADE experiments (Experiment 9) demonstrated that doses of GET73 equal to or higher than $5 \mathrm{mg} / \mathrm{kg}$ suppressed the additional amount of alcohol (65-80\% of baseline in the present series of experiments) consumed by sP rats after a period of alcohol deprivation; these increases are thought to model relapse drinking episodes and loss of control over alcohol in human alcoholics (see Spanagel, 2005).

The reducing effect of GET73 in "maintenance" and ADE experiments was specific for alcohol intake, as water and food intake was never affected, even minimally, by treatment with GET73. These data are moreover of relevance as they tend to exclude the possibility that GET73-induced reduction in alcohol intake was secondary to sedation or malaise. This conclusion is further strengthened by the results of Experiment 3, demonstrating that doses of GET73 up to $50 \mathrm{mg} / \mathrm{kg}$ did not affect, even minimally, spontaneous locomotor activity in SD rats, suggesting a wide separation between the doses of GET73 exerting the "desired" pharmacological effects and those producing "adverse" effects.

Recent data demonstrated that repeated treatment with doses of GET73 ranging between 10 and $200 \mathrm{mg} / \mathrm{kg}$ markedly reduced sucrose intake (Tacchi et al., 2008) and consumption of highly palatable foods (Ottani et al., 2007) in Wistar rats. The reducing effect on palatable food was associated to an increased consumption of regular food pellets, indicating the specificity of GET73 action on the hedonic components of food intake. These data,

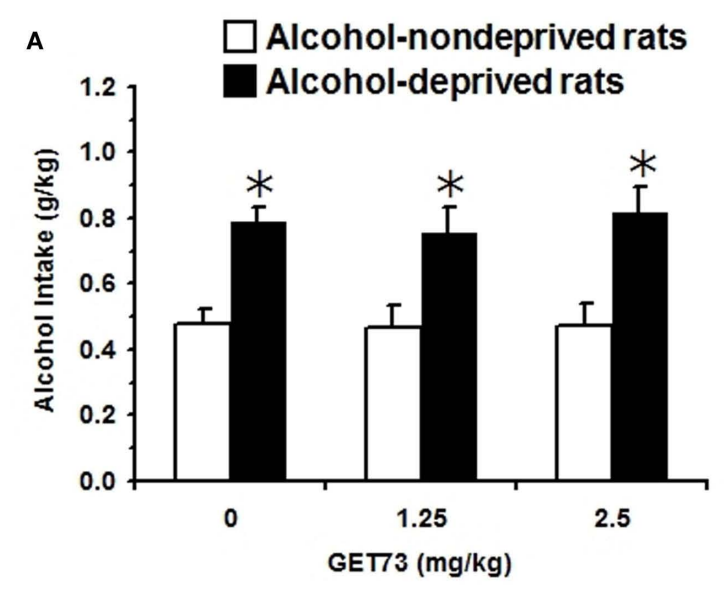

B

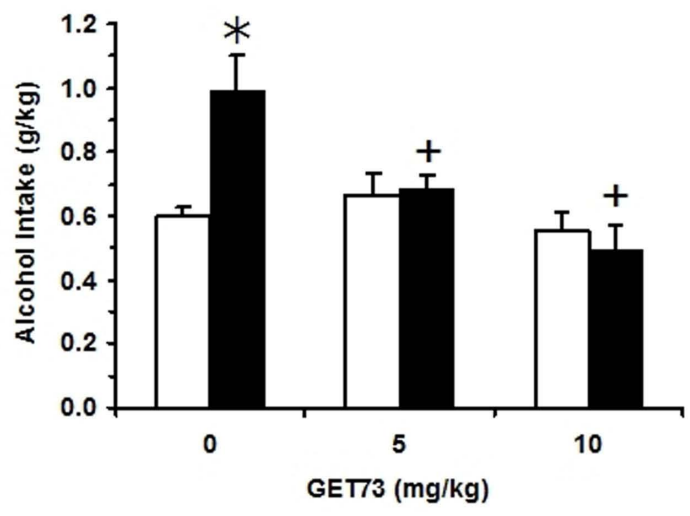

C

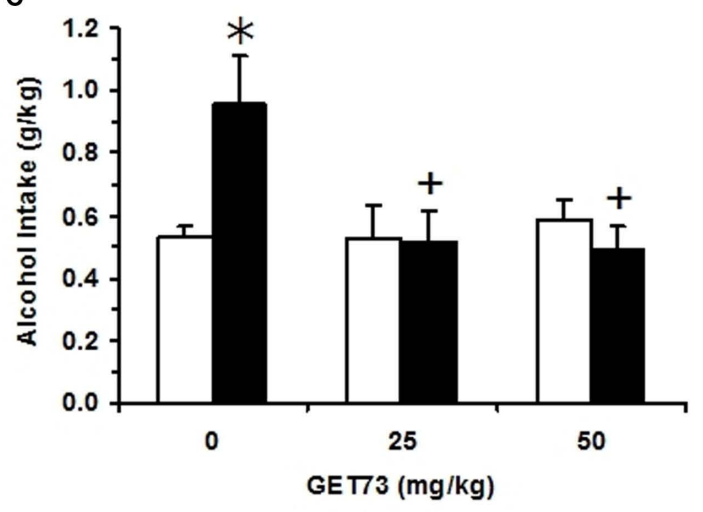

FIGURE 8 | Effect of the acute, intragastric administration of low (A), moderate (B), and high doses (C) of GET73 - tested in three independent experiments - on the "alcohol deprivation effect" (ADE) in Sardinian alcohol-preferring (sP) rats. Alcohol (10\% v/v, in water) was offered under the standard, homecage two-bottle "alcohol vs water" choice regimen with unlimited access for $24 \mathrm{~h} /$ day. Alcohol-deprived rats were deprived of alcohol for 14 consecutive days; alcohol-non-deprived rats had continuous access to alcohol and water. Thirty minutes before representation of the alcohol bottle (which coincided with lights off), both alcohol-deprived and -non-deprived rats were treated acutely with GET73. Alcohol intake was registered 60 min after lights off. Each bar is the mean \pm SEM of $n=7-18$. ${ }^{*} P<0.05$ with respect to alcohol-non-deprived rats receiving $0 \mathrm{mg} / \mathrm{kg}$ GET73 (Newman-Keuls test); ${ }^{+P}<0.05$ with respect to alcohol-deprived rats receiving $0 \mathrm{mg} / \mathrm{kg} \mathrm{GET73} \mathrm{(Newman-Keuls} \mathrm{test).}$ 
together with those generated by Experiments 8 and 9 of the present study, suggest that GET73 may be capable of interfering with different reward-related behaviors in rats.

Comorbidity of AUDs and psychiatric disorders, including panic disorders, generalized anxiety, and post-traumatic stress disorders, is a well-documented clinical feature (see Grant et al., 2004), often requiring complex treatment strategies. It was therefore of interest to assess the anxiolytic potential of GET73. Accordingly, Experiment 7 evaluated the effect of a large spectrum of GET73 doses $(5-50 \mathrm{mg} / \mathrm{kg}$ ) in SD and sP rats exposed to the EPM test, one of the most widely used procedures in the assessment of anxiety-related behaviors in rodents. Data from the EPM experiments indicate that (a) treatment with GET73 produced a clear anxiolytic effect in both SD (Experiment 7a) and sP (Experiment 7b) rats, (b) the effect of GET73 was a bell-shaped function of its dose, and (c) this pattern was particularly evident in sP rats. Differences in basal, emotional states and behavioral profile of SD and sP rats might explain the differential effect of GET73 in the two rat lines at the EMP test. Further, Experiments 7a (SD rats) and 7b (sP rats) were conducted in two different locations (Sanremo and Cagliari, respectively); although maximal care was taken to minimize differences in the experimental procedures, it cannot be ruled out that the differences observed between SD and sP rats were due, at least in part, to slight methodological differences between the two laboratories.

Rats of the sP lines have been found to display high levels of inherent anxiety-related behaviors in multiple experimental procedures, including the EPM test (Colombo et al., 1995; Richter et al., 2000; Agabio et al., 2001; Cagiano et al., 2002; Leggio et al., 2003; Roman and Colombo, 2009; Roman et al., 2012). Voluntarily consumed alcohol reduced anxiety-related behaviors in $\mathrm{sP}$ rats (Colombo et al., 1995), suggesting that these rats may consume alcohol to ameliorate their high negative emotional states. Accordingly, it can be hypothesized that the anxiolytic effect of GET73 could "substitute," at least in part, for the anxiolytic effect of alcohol sought by sP rats, contributing toward reducing voluntary alcohol intake in this rat line. In agreement with this hypothesis, drugs exerting anxiolytic effects in $\mathrm{sP}$ rats have also been found to reduce alcohol drinking: as an example, acute administration of non-sedative doses of GHB suppressed anxiety-related behaviors in sP rats exposed to the EPM test (Agabio et al., 1998) and reduced alcohol intake (Agabio et al., 1998) and operant, oral alcohol selfadministration (Maccioni et al., 2008) in sP rats. Application of this "substitution" hypothesis to GET73 is somehow challenged by the lack of anxiolytic effect exerted by the highest tested dose of GET73 (50 mg/kg), that - conversely - reduced alcohol intake (in both "maintenance" and ADE experiments) to an extent comparable to that of the two "anxiolytic" doses of GET73 (10 and $25 \mathrm{mg} / \mathrm{kg}$ ). This discrepancy might be explained by the involvement of additional mechanism(s) and/or active metabolite(s) of GET73.

A series of experiments (namely, Experiments 4-6) investigated the effect of treatment with GET73 on different cognitive functions in SD rats. In all three experiments, the tested dose-range of GET73 was comparable to those found to exert anti-alcohol effects in sP rats (Experiments 8 and 9) and anxiolytic effects in SD and sP rats
(Experiment 7); further, these doses were devoid of any hypolocomotor and sedative effect in SD rats, as demonstrated by the results of Experiment 3. Results of Experiments 4 and 5 indicated that treatment with GET73 failed to alter the cognitive processes involved in both Passive and Active Avoidance tasks.

A more complex picture can be drawn from the results of Experiment 6, in which SD rats treated with different doses of GET73 were exposed to a modified water version of the Hebb-Williams maze test. GET73 tended to exert a biphasic effect on spatialmemory performance, with promnestic and amnestic effects as the dose was increased. Specifically: (a) treatment with low doses of GET73 (5 and $10 \mathrm{mg} / \mathrm{kg}$ ) increased the rat ability to find the maze exit, as suggested by significant reductions, in several sessions, in number of swimming reversals, number of working-memory errors, and distance traveled to reach the exit zone; (b) treatment with a high dose of GET73 $(50 \mathrm{mg} / \mathrm{kg})$ resulted in increases in number of entries into the blind alleys, number of swimming reversals, number of working-memory errors, and distance traveled to reach the exit zone in several sessions, suggesting a perseveration in making the same errors and a clear impairment in the spatial-map acquisition and consolidation.

The exact mechanism of action underlying the multiple behavioral effects of GET73 is presently unknown. GET73 was designed as a possible analog or derivative of GHB; however, data from Experiments 1 indicated that GET73 was devoid of any affinity for GHB binding sites (low and high affinity).

Experiment 2 explored the possibility that GET73 could bind to multiple receptor and uptake systems known to be part of the neural substrates involved in reward, drug addiction, emotional states, and cognition. However, data failed to demonstrate any functionally meaningful affinity of GET73 for dopamine $\mathrm{D}_{1}$, $\mathrm{D}_{2}$, and $\mathrm{D}_{3}$ receptors, serotonin $5-\mathrm{HT}_{1}, 5-\mathrm{HT}_{2}$, and $5-\mathrm{HT}_{3}$ receptors, $\mathrm{GABA}_{\mathrm{A}}$ and $\mathrm{GABA}_{\mathrm{B}}$ receptors, benzodiazepine binding site, chloride channel, ionotropic glutamate receptors, dopamine, and serotonin reuptake sites. These results leave the question on the mode of action of GET73 still open.

More recent in vitro neurochemical studies however lead to the advancing of an additional hypothesis. It has indeed been found that GET73 may influence glutamate neurotransmission in the CA1 region of the rat hippocampus, this effect being mediated via the subtype 5 of the metabotropic glutamate (mGlu5) receptor (Ferraro et al., 2011). Notably, different drugs interacting with the mGlu5 receptor (such as the mGlu5 receptor antagonists, MPEP and MTEP) have been repeatedly reported to (a) reduce alcohol intake and operant alcohol self-administration (e.g., Cowen et al., 2007; Besheer et al., 2008; Sidhpura et al., 2010), (b) exert anxiolytic effects (e.g., Ballard et al., 2005; Varty et al., 2005; Pérez de la Mora et al., 2006), and (c) induce complex effects on various learning and memory tasks (e.g., Campbell et al., 2004; Homayoun et al., 2004; Ballard et al., 2005) in rats and mice, displaying a profile that is - to some extent - similar to that of GET73.

In conclusion, the results of the present study suggest that GET73 exerted anti-alcohol and anxiolytic effects in rats. Future clinical studies will assess whether GET73 may represent a potential pharmacotherapy for alcohol dependence and associated anxiety disorders. 


\section{REFERENCES}

Addolorato, G., Balducci, G., Capristo, E., Attilia, M. L., Taggi, G., Gasbarrini, G., and Ceccanti, M. (1999). Gamma-hydroxybutyric acid (GHB) in the treatment of alcohol withdrawal syndrome: a randomized comparative study versus benzodiazepine. Alcohol. Clin. Exp. Res. 23, 1596-1604.

Addolorato, G., Castelli, E., Stefanini, G. F., Casella, G., Caputo, F., Marsigli, L., Bernardi, M., and Gasbarrini, G. (1996). An open multicentric study evaluating 4-hydroxybutyric acid sodium salt in the medium-term treatment of 179 alcohol dependent subjects. Alcohol Alcohol. 31, 341-345.

Addolorato, G., Cibin, M., Capristo, E., Beghé, F., Gessa, G., Stefanini, G. F., and Gasbarrini, G. (1998a). Maintaining abstinence from alcohol with gamma-hydroxybutyric acid. Lancet 351, 38 .

Addolorato, G., Cibin, M., Caputo, F., Capristo, E., Gessa, G. L., Stefanini, G. F., and Gasbarrini, G. (1998b). (-Hydroxybutyric acid in the treatment of alcoholism: dosage fractioning utility in non-responder alcoholic patients. Drug Alcohol Depend. 53, 7-10.

Addolorato, G., Leggio, L., Ferrulli, A., Caputo, F., and Gasbarrini, A. (2009). The therapeutic potential of gamma-hydroxybutyric acid for alcohol dependence: balancing the risks and benefits. A focus on clinical data. Expert Opin. Investig. Drugs 18, 675-686.

Agabio, R., Carai, M. A. M., Gessa, G. L., and Colombo, G. (2010). " $\gamma$-Hydroxybutyric acid (GHB)," in Encyclopedia of Behavioral Neuroscience, Vol. 2, eds G. F. Koob, M. Le Moal, and R. F. Thompson (Oxford: Academic Press), 76-83.

Agabio, R., Carai, M. A. M., Lobina, C. Pani, M., Reali, R., Vacca, G., Gessa, G. L., and Colombo, G. (2001). Alcohol stimulates motor activity in selectively bred Sardinian alcoholpreferring (sP), but not in Sardinian alcohol-nonpreferring (sNP), rats. Alcohol 23, 123-126.

Agabio, R., Colombo, G., Loche, A., Lobina, C., Pani, M. L., Reali, R., and Gessa, G. L. (1998). (Hydroxybutyric acid reducing effect on ethanol intake: evidence in favour of a substitution mechanism. Alcohol Alcohol. 33, 465-474.

Agabio, R., and Gessa, G. L. (2002). "Therapeutic uses of (-hydroxybutyrate," in GammaHydroxybutyrate: $\quad$ Molecular, Functional and Clinical Aspects, eds G. Tunnicliff and C. D. Cash (London: Taylor and Francis), 169-187.

Andresen, H., Aydin, B. E., Mueller, A., and Iwersen-Bergmann, S. (2011). An overview of gamma-hydroxybutyric acid: pharmacodynamics, pharmacokinetics, toxic effects, addiction, analytical methods, and interpretation of results. Drug Test. Anal. 3, 560-568.

Ballard, T. M., Woolley, M. L., Prinssen, E., Huwyler, J., Porter, R., and Spooren, W. (2005). The effect of the mGlu5 receptor antagonist MPEP in rodent tests of anxiety and cognition: a comparison. Psychopharmacology (Berl.) 179, 218-229.

Bennet, J. P., and Snyder, S. H. (1976). Serotonin and lysergic acid diethylamide binding in rat brain membranes: relationship to postsynaptic serotonin receptors. Mol. Pharmacol. 12, 373-389.

Besheer, J., Faccidomo, S., Grondin, J. J., and Hodge, C. W. (2008). Regulation of motivation to selfadminister ethanol by mGluR5 in alcohol-preferring (P) rats. Alcohol. Clin. Exp. Res. 32, 209-221.

Billard, W., Ruperto, V., Crosby, G., Iorio, L. C., and Barnett, A. (1984). Characterization of the binding of [3H]-SCH 23390, a selective D1 receptor antagonist ligand. Life Sci. 35, 1885-1893.

Bradford, M. M. (1976). Rapid and sensitive method for the quantitation of microgram quantities of protein utilizing the principle of protein-dye binding. Anal. Biochem. 72, 248-254.

Cagiano, R., Cassano, T., Coluccia, A., Gaetani, S., Giustino, A., Steardo, L., Tattoli, M., Trabace, L., and Cuomo, V. (2002). Genetic factors involved in the effects of developmental low-level alcohol induced behavioral alterations in rats. $\mathrm{Neu}$ ropsychopharmacology 26, 191-203.

Campbell, U. C., Lalwani, K., Hernandez, L., Kinney, G. G., Conn, P. J., and Bristow, L. J. (2004). The mGluR5 antagonist 2-methyl6-(phenylethynyl)-pyridine (MPEP) potentiates PCP-induced cognitive deficits in rats. Psychopharmacology (Berl.) 175, 310-318.

Caputo, F., Bernardi, M., and Zoli, G. (2010). "Gamma hydroxybutyric acid (GHB): a valid pharmacological opportunity for the treatment of alcohol dependence," in Advances in Psychology Research, Vol. 66, ed. A. M. Columbus (Nova Science Publishers), 317-330.

Carai, M. A. M., Colombo, G., Reali, R., Serra, S., Mocci, I.,
Castelli, M. P., Cignarella, G. and Gessa, G. L. (2002). Central effects of 1,4-butanediol are mediated by $\mathrm{GABA}(\mathrm{B})$ receptors via its conversion into gammahydroxybutyric acid. Eur. J. Pharmacol. 446, 157-163.

Carter, L. P., Koek, W., and France, C. P. (2009). Behavioral analyses of GHB: receptor mechanisms. Pharmacol. Ther. 121, 100-114.

Castelli, M. P., Ferraro, L., Mocci, I., Carta, F., Carai, M. A. M., Antonelli, T., Tanganelli, S., Cignarella, G., and Gessa, G. L. (2003). Selective $\gamma$ hydroxybutyric acid receptor ligands increase extracellular glutamate in the hippocampus, but fail to activate $G$ protein and to produce the sedative/hypnotic effect of $\gamma$ hydroxybutyric acid. J. Neurochem. 87, 722-723.

Chick, J., and Nutt, D. (2012). Substitution therapy for alcoholism: time for a reappraisal? J. Psychopharmacol. 26, 205-212.

Chiu, T. H., and Rosemberg, H. C. (1983). Conformational changes in benzodiazepine receptors induced by the antagonist Ro 15-1788. Mol. Pharmacol. 23, 289-294.

Colombo, G., Agabio, R., Lobina, C., Reali, R., Zocchi, A., Fadda, F., and Gessa, G. L. (1995). Sardinian alcohol-preferring rats: a genetic animal model of anxiety. Physiol. Behav. 57, 1181-1185.

Colombo, G., Lobina, C., Carai, M. A. M., and Gessa, G. L. (2006). Phenotypic characterization of genetically selected Sardinian alcoholpreferring $(\mathrm{sP})$ and -non preferring (sNP) rats. Addict. Biol. 11, 324-338.

Corda, M. G., Cancedda, E., and Giorgi, O. (1993). Modulation of [35S]TBPS binding by GABAergic drugs in the cerebral cortex of newborn and adult rats. Brain Res. Bull. 32, 647-652.

Cowen, M. S., Krstew, E., and Lawrence, A. J. (2007). Assessing appetitive and consummatory phases of ethanol self-administration in C57BL/6 J mice under operant conditions: regulation by mGlu5 receptor antagonism. Psychopharmacology (Berl.) 190, 21-29.

Eichenbaum, H. (2001). The hippocampus and declarative memory: cognitive mechanisms and neural codes. Behav. Brain Res. 127, 199-207.

Enna, S. J., and Snyder, S. H. (1977). Influences of ions, enzymes, and detergents on $\gamma$-aminobutyric acidreceptor binding in synaptic membranes of rat brain. Mol. Pharmacol. 13, 442-453.
Ferraro, L., Beggiato, S., Tomasini, M. C., Antonelli, T., Loche, A., and Tanganelli, S. (2011). GET73 modulates rat hippocampal glutamate transmission: evidence for a functional interaction with mGluR5. Pharmacol. Rep. 63, 1359-1371.

Fields, J. Z., Reisine, T. D., and Yamamura, H. I. (1977). Loss of striatal dopaminergic receptors after intrastriatal kainic acid injection. Brain Res. 136, 578-584.

Gallimberti, L., Canton, G., Gentile, N., Ferri, M., Cibin, M., Ferrara, S. D. Fadda, F., and Gessa, G. L. (1989). Gamma-hydroxybutyric acid for treatment of alcohol withdrawal syndrome. Lancet 2, 787-789.

Gallimberti, L., Ferri, M., Ferrara, S. D., Fadda, F., and Gessa, G. L. (1992). Gamma-hydroxybutyric acid in the treatment of alcohol dependence: a double-blind study. Alcohol. Clin. Exp. Res. 16, 673-676.

Glisson, J. K., and Norton, J. (2002). Self-medication with gammahydroxybutyrate to reduce alcohol intake. South Med. J. 95, 926-928.

Grant, B. F., Stinson, F. S., Dawson, D. A., Chou, S. P., Dufour, M. C., Compton, W., Pickering, R. P., and Kaplan, K. (2004). Prevalence and co-occurrence of substance use disorders and independent mood and anxiety disorders. Results from the national epidemiologic survey on alcohol and related conditions. Arch. Gen. Psychiatry 61, 807-816.

Hebb, D. O., and Williams, K. (1946). A method of rating animal intelligence. J. Gen. Psychol. 34, 59-65.

Herschel, M., and Baldessarini, R. J. (1979). Evidence for two types of binding of $[3 \mathrm{H}]-\mathrm{GABA}$ and $[3 \mathrm{H}]$ muscimol in rat cerebral cortex and cerebellum. Life Sci. 24, 1849-1854.

Hogg, S. (1996). A review of the validity and variability of the elevated plusmaze as an animal model of anxiety. Pharmacol. Biochem. Behav. 54, 21-39.

Homayoun, H., Stefani, M. R., Adams, B. W., Tamagan, G. D., and Moghaddam, B. (2004). Functional interaction between NMDA and mGlu5 receptors: effects on working memory, instrumental learning, motor behaviors, and dopamine release. Neuropsychopharmacology 29, 1259-1269.

June, H. L., Williams, J. A., Cason, C. R., Devaraju, S., Lin, M., Murphy, J. M., Lewis, M. J., Lumeng, L. and Li, T.-K. (1995). Low doses of gamma-hydroxybutyric acid (GHB) attenuate ethanol intake in alcoholpreferring (P) rats. Alcohol. Clin. Exp. Res. 19(Suppl. 2), 14A. 
Kilpatrick, G. J., Jones, B. J., and Tyers, M. B. (1987). Identification and distribution of $5 \mathrm{HT} 3$ receptors in rat brain using radioligand binding. Nature 330, 746-748.

Kobayashi, S., Ohashi, Y., and Ando, S. (2002). Effects of enriched environments with different durations and starting times on learning capacity during aging in rats assessed by a refined procedure of the HebbWilliams maze task. J. Neurosci. Res. 70, 340-346.

Krishnan-Sarin, S., O'Malley, S., and Krystal, J. H. (2008). Treatment implications: using neuroscience to guide the development of new pharmacotherapies for alcoholism. Alcohol Res. Health 31, 400-407.

Leggio, B., Masi, F., Grappi, S., Nanni, G., Gambarana, C., Colombo, G., and de Montis, M. G. (2003). Sardinian alcohol-preferring and nonpreferring rats show different reactivity to aversive stimuli and a similar response to a natural reward. Brain Res. 973, 275-284.

Lévesque, D., Diaz, J., Pilon, C., Martres, M. P., Giros, B., Souil, E., Schott, D., Morgat, J. L., Schwartz, J. C., and Sokoloff, P. (1992). Identification, characterization, and localization of the dopamine D3 receptor in rat brain using 7-[3H]hydroxyN,N-di-n-propyl-2-aminotetralin. Proc. Natl. Acad. Sci. U.S.A. 89, 8155-8159.

Leysen, J. E., Niemegeers, C. J. E., Van Nueten, J. M., and Ladurom, P. M. (1981). [3H]-ketanserin (R41,468), a selective [3H]-ligand for serotonin2 receptor binding sites. Mol. Pharmacol. 21, 301-314.

Maccioni, P., Pes, D., Fantini, N., Carai, M. A. M., Gessa, G. L., and Colombo, G. (2008). $\quad \gamma$-Hydroxybutyric acid (GHB) suppresses alcohol's motivational properties in alcohol-preferring rats. Alcohol 42, 107-113.

Marcusson, J. O., Bergström, M., Eriksson, K., and Ross, S. B. (1988). Characterization of [3H]-paroxetine binding in rat brain. J. Neurochem. 50, 1783-1790.
Monaghan, D. T., and Cotman, C. W. (1982). The distribution of $[3 \mathrm{H}]$ kainic acid binding sites in rat CNS as determined by autoradiography. Brain Res. 252, 91-100.

Moncini, M., Masini, E., Gambassi, F., and Mannaioni, P. F. (2000). Gamma-hydroxybutyric acid and alcohol-related syndromes. Alcohol 20, 285-291.

Murphy, D. E., Snowhill, E. W., and Williams, M. (1987). Characterization of quisqualate recognition sites in rat brain tissue using DL- $[3 \mathrm{H}]$ alpha-amino-3-hydroxy5-methyl-isoxazole-4-propionic acid (AMPA) and a filtration assay. Neurochem. Res. 12, 775-782.

Nimmerrichter, A. A., Walter, H., Gutierrez-Lobos, K. E., and Lesch, O. M. (2002). Double-blind controlled trial of $\gamma$-hydroxybutyrate and clomethiazole in the treatment of alcohol withdrawal. Alcohol Alcohol. 37, 67-73.

Olton, D. S., Becker, J. T., and Handelman, G. E. (1979). Hippocampus, space and memory. Behav. Brain Sci. 2, 313-322.

O'Malley, S. S., and O'Connor, M. D. (2011). Medications for unhealthy alcohol use. Alcohol Res. Health 33, 300-311.

Ottani, A., Leone, S., Vergara, F. B., Tacchi, R., Loche, A., and Bertolini, A. (2007). Preference for palatable food is reduced by the gammahydroxybutyrate analogue GET73, in rats. Pharmacol. Res. 55, 271-279.

Pérez de la Mora, M., Lara-García, D., Jacobsen, K. X., Vázquez-García, M., Crespo-Ramírez, M., Flores-Gracia, C., Escamilla-Marvan, E., and Fuxe, K. (2006). Anxiolytic-like effects of the selective metabotropic glutamate receptor 5 antagonist MPEP after its intra-amygdaloid microinjection in three different non-conditioned rat models of anxiety. Eur. J. Neurosci. 23, 2749-2759.

Richter, R. M., Zorrilla, E. P., Basso, A. M., Koob, G. F., and Weiss, F. (2000). Altered amygdalar CRF release and increased anxiety-like behavior in Sardinian alcohol-preferring rats: a microdialysis and behavioral study. Alcohol. Clin. Exp. Res. 24 1765-1772.

Rodgers, R. J., Cao, B.-J., Dalvi, A., and Holmes, A. (1997). Animal models of anxiety: an ethological perspective. Braz. J. Med. Biol. Res. 30, 289-304.

Roman, E., and Colombo, G. (2009) Lower risk taking and exploratory behavior in alcohol-preferring $\mathrm{sP}$ rats than in alcohol non-preferring sNP rats in the multivariate concentric square fieldä (MCSF) test. Behav. Brain Res. 205, 249-258.

Roman, E., Stewart, R. B., Bertholomey, M. L., Jensen, M. L., Colombo, G. Hyytiä, P., Badia-Elder, N. E., Grahame, N. J., Li, T.-K., and Lumeng, L. (2012). Behavioral profiling of multiple pairs of rats selectively bred for high and low alcohol intake using the MCSF test. Addict. Biol. 17, 33-46.

Sidhpura, N., Weiss, F., and MartinFardon, R. (2010). Effects of the mGlu2/3 agonist LY379268 and the mGlu5 antagonist MTEP on ethanol seeking and reinforcement are differentially altered in rats with a history of ethanol dependence. Biol. Psychiatry 67, 804-811.

Sills, M. A., Faag, G., Pozza, M., Angst, C., Brundish, D. E., Hurt, S. D., Wilusz, E. J., and Williams, M (1991). [3H]CGP 39653: a new Nmethyl-D-aspartate antagonist radioligand with low nanomolar affinity in brain. Eur. J. Pharmacol. 192, 19-24.

Snead, O. C. III, and Gibson, K. M. (2005). $\gamma$-Hydroxybutyric acid. $N$ Engl. J. Med. 352, 2721-2732.

Spanagel, R. (2005). "How to measure relapse in animals," in Drugs for Relapse Prevention of Alcoholism, eds R. Spanagel and K. Mann (Basel: Birkäuser Verlag), 13-21.

Tacchi, R., Ferrari, A., Loche, A., and Bertolini, A. (2008). Sucrose intake: increase in non-stressed rats and reduction in chronically stressed rats are both prevented by the gammahydroxybutyrate (GHB) analogue, GET73. Pharmacol. Res. 57, 464-468.
Valchar, M., and Hanbauer, I. (1993). Comparison of [3H]WIN 35,428 binding, a marker for dopamine transporter, in embryonic mesencephalic neuronal cultures with striatal membranes of adult rats. $J$. Neurochem. 60, 469-476.

Varty, G. B., Grilli, M., Forlani, A., Fredduzzi, S., Grzelak, M. E., Guthrie, D. H., Hodgson, R. A., Lu, S. X., Nicolussi, E., Pond, A. J., Parker, E. M. Hunter, J. C., Higgins, G. A., Reggiani, A., and Bertorelli, R. (2005). The antinociceptive and anxiolyticlike effects of the metabotropic glutamate receptor 5 (mGluR5) antagonists, MPEP and MTEP, and the mGluR1 antagonist, LY456236, in rodents: a comparison of efficacy and side-effect profiles. Psychopharmacology (Berl.) 179, 207-217.

Yoneda, Y., and Kuriyama, K. (1980). Presence of low molecular weight endogenous inhibitor on $[3 \mathrm{H}]$ muscimol binding in synaptic membranes. Nature 285, 670-673.

Conflict of Interest Statement: The authors declare that the research was conducted in the absence of any commercial or financial relationships that could be construed as a potential conflict of interest.

Received: 16 December 2011; accepted: 30 January 2012; published online: 14 February 2012.

Citation: Loche A, Simonetti F, Lobina C, Carai MAM, Colombo G, Castelli MP, Barone D and Cacciaglia R (2012) Antialcohol and anxiolytic properties of a new chemical entity, GET73. Front. Psychiatry 3:8. doi: 10.3389/fpsyt.2012.00008

This article was submitted to Frontiers in Addictive Disorders, a specialty of Frontiers in Psychiatry.

Copyright (C) 2012 Loche, Simonetti, Lobina, Carai, Colombo, Castelli, Barone and Cacciaglia. This is an open-access article distributed under the terms of the Creative Commons Attribution Non Commercial License, which permits noncommercial use, distribution, and reproduction in other forums, provided the original authors and source are credited. 